\title{
An Intra-Group Perspective on Leader Preferences: \\ Different Risks of Exploitation Shape Preferences for \\ Leader Facial Dominance
}

Troels Bøggild ${ }^{\mathrm{a}} \&$ Lasse Laustsen ${ }^{\mathrm{a}}$

Bartholins Allé 7, 8000 Aarhus C, Denmark

${ }^{a}$ Department of Political Science,

Aarhus University, Denmark

tboeggild@ps.au.dk / $\underline{11 @ p s . a u . d k}$

Accepted for publication in The Leadership Quarterly

* Corresponding author: tboeggild@ps.au.dk 


\begin{abstract}
:
This article argues that followers' preferences for dominant leadership vary according to two types of exploitation risks from other individuals within the group. Previous work demonstrates that contexts of inter-group war and peace make followers prefer dominant- and non-dominant-looking leaders, respectively. We add an intra-group perspective to this literature. Four original studies demonstrate that contexts with high risks of free-riding and criminal behavior from other group members (i.e., horizontal exploitation) increase preferences for dominant-looking leaders, whereas contexts with high risks of unresponsive, self-interested behavior from leaders themselves (i.e., vertical exploitation) decrease preferences for dominant-looking leaders. Moreover, within this framework of intra-group exploitation risks we show that followers prefer leaders from another visà-vis their own ethnic coalition to look less dominant, and that this difference is driven by enhanced concerns for vertical exploitation from ethnically different leaders. The findings add new insights on appearance-based voting and electoral difficulties facing minority candidates.
\end{abstract}

Keywords: Leader dominance, evolutionary psychology, appearance-based voting, coalitional psychology, minority political candidates 


\section{Introduction}

Political candidates are among the key actors in modern democracies and democratic elections. Extant research demonstrates that political candidates attract and repel voters not just as a result of their policy positions and political achievements but also by means of their perceived character traits (Popkin, 1994; Funk, 1999; Hayes, 2005). In addition, research over the last decade has demonstrated that trait inferences of competence, attractiveness, and dominance made by regular people — even little children — based solely on candidates' faces predict electoral outcomes of realworld elections (Todorov, Mandisodza, Goren, \& Hall, 2005; Antonakis \& Dalgas, 2009; Cogsdill, Todorov, Spelke, \& Banaji, 2014; Laustsen \& Petersen, 2016; for useful overviews see Olivola \& Todorov, 2010a; Poutvaara, 2014). Outside the political domain studies have also found that people turn to facial appearance when evaluating and choosing among potential leaders, for example in corporate, military, and sports settings (Rule \& Tskhay, 2014; Olivola, Eubanks, \& Lovelace, 2014). Building on evolutionary psychology, scholars theorize that these effects of trait inferences from leaders' facial appearance reflect an evolved psychological system of followership that is flexibly responsive to contextual conditions of inter-group conflict and peace (Van Vugt, Hogan, \& Kaiser, 2008; Spisak, Dekker, Krüger, \& Van Vugt, 2012a; Little, Burriss, Jones, \& Roberts, 2007; Little, Roberts, Jones, \& Debruine, 2012; von Rueden \& van Vugt, 2015; Vugt \& Grabo, 2015; Laustsen \& Petersen, 2015). Specifically, results show that dominant and masculine candidates are preferred under conditions of inter-group conflict and war, whereas feminine and less dominant candidates are preferred in contexts of inter-group cooperation and peace (Little et al., 2007; Hall, Gore, Chaiken, \& Todorov, 2009; Little et al., 2012; Spisak et al., 2012a; Spisak, Homan, Grabo, \& Van Vugt, 2012b; Laustsen \& Petersen, 2016).

In this paper, we add an intra-group perspective to this literature on preferences for leader traits. Specifically, we build on prior work (e.g., von Rueden, Gurven, Kaplan, \& Stieglitz, 2014; von 
Rueden \& van Vugt, 2015) and argue that followers adjust their preferences for leader dominance not only according to conditions of inter-group conflict and peace but also according to different risks of exploitation posed by other individuals within the group. From this basic argument we derive three concrete and interrelated predictions. First, we expect that contexts with high risks of free-riding and criminal behavior from other group members (i.e., horizontal exploitation) increase followers' preferences for a dominant-looking leader whereas contexts with high risks of unresponsive and self-interested behavior from leaders themselves (i.e., vertical exploitation) increase preferences for a non-dominant-looking leader. Second, we predict that followers will prefer leaders who belong to a different ethnic coalition than themselves to look less dominant than leaders who belong to their own coalition because the former are perceived as more likely to engage in vertical exploitation against the follower. And third, this leads us to expect that followers' tendency to prefer leaders from different ethnic groups to look less dominant will be intensified under contexts characterized by high risks of vertical exploitation (i.e., when risks of exploitation are posed by the leader) compared to contexts with high risks of horizontal exploitation (i.e., when risks of exploitation are not posed by the leader).

Four original experimental studies carried out in Denmark and the US support the three predictions and, thus, our basic argument that preferences for leader traits are flexibly and strategically designed to shield the follower from threats coming not only from other groups but also from within the follower's own group. Further implications for research on face-based trait inferences of leaders and political candidates are discussed as are the potential electoral challenges facing ethnic minority candidates.

\section{Evolutionary followership psychology}


A number of studies find that contexts of war and inter-group conflict cause individuals to hold stronger preferences for masculine and dominant-looking leaders than contexts of peace and intergroup cooperation (Little et al., 2007; Hall et al., 2009; Spisak et al., 2012a; Little et al., 2012; Laustsen \& Petersen, 2015). This research shows, in line with implicit leadership theory, that followers hold implicit, preconceived notions and expectations about the traits and qualities that leaders should possess (Schyns \& Meindl, 2005) and, in line with contingency models of leadership, that such notions and expectations vary according to the situation or problem facing the group (Fiedler, 1964; Thompson \& Vecchio, 2009). Building on these leadership theories, scholars have taken followers' attention to physical cues of leader dominance as evidence of an evolved psychological system of followership (Little et al., 2007; Spisak et al., 2012a; Van Vugt \& Grabo, 2015; Laustsen \& Petersen, 2015). That is, evolution is believed to have installed context-specific leader prototypes in the minds of followers associating certain features of leaders - for instance dominant and non-dominant faces — with specific contextual problems such as war and peace (Spisak et al., 2012a; Van Vugt \& Grabo, 2015; von Rueden \& van Vugt, 2015; Laustsen \& Petersen, 2015).

One central feature of these studies is that the contextual variation always relates to inter-group relations and different degrees of group conflict. However, according to research on the origins of leadership and followership, evolutionary problems of inter-group relations are not exclusively responsible for shaping human leader preferences and, thus, our evolved followership psychology (De Cremer \& Van Vugt, 2002; Van Vugt et al., 2008; King, Johnson, \& Van Vugt, 2009). Rather, this literature argues that leadership also evolved to handle — and still serves to handle — a multitude of problems related distinctly to intra-group phenomena such as maintaining peace within the group and facilitating mutual trust among fellow group members (Boehm, 1999; Davey, 1998; Van Vugt \& De Cremer, 1999; Cummins, 2009). Against this backdrop, we form our basic argument that 
preferences for leader dominance are also flexibly responsive to social problems originating within the follower's group — in particular from threats related to anti-social, exploitative behaviors from other group members. In other words, preferences for leader dominance are strategically designed to shield the individual from threats related to exploitation on the part of other individuals within the group. Below we outline three interrelated predictions that follow from this basic argument.

Risks of exploitation, leader dominance, and the trade-off facing followers

Like contexts of war and peace have required leaders with different qualities — and hence, invoked different leader prototypes in the minds of followers (e.g., dominant and non-dominant) we expect that two distinct risks of exploitation from other individuals within the group have done the same. These two types of exploitation stem from other rank-and-file group members and from the leader, respectively.

The first type of exploitation stems from other ordinary group members. A key insight in evolutionary psychology is that successful within-group cooperation has been of major importance for the survival of any individual. That is, by cooperating with fellow group members the individual would be better able to buffer against failed foraging, acquire food in times of injury and sickness, and produce collective goods such as shelter (Tooby \& Cosmides, 1992; Sugiyama, 2004; Kaplan \& Gurven, 2005). However, such reliance on others would also have introduced the risk of freeriding and norm-violating behaviors — or even criminal acts such as theft and murder — intentionally or unintentionally directed at and harming the individual (Cosmides \& Tooby, 2005). We label this type of exploitation horizontal exploitation since such risks originate from other rank-and-file group members and their behaviors.

In contexts where risks of horizontal exploitation are particularly high, we expect that group members should want a dominant group leader to oversee everybody's contribution to the 
production of public goods and punitively sanction any deviant behaviors in this respect. In ancestral human groups leaders are assumed to have played a central role for conflict intervention and for sanctioning norm violators to ensure intra-group peace and tranquility (Van Vugt et al., 2008; King et al., 2009; von Rueden \& van Vugt, 2015). This leadership role is also prevalent among other primates including chimpanzees and macaques in which the alpha-male performs third-party interventions to break up intra-group feuds to maintain social order within the group (De Waal, 1997; Flack et al., 2006; von Rohr et al., 2012). Dominant individuals typically possess both the physical capabilities and the motivational drive to engage in inter-personal conflicts (De Waal, 1997; Sell, Tooby, \& Cosmides, 2009; von Rueden et al., 2014), and anthropological studies have found that such qualities are important in a leadership role to suppress free-riding and criminal behavior among group followers in small-scale groups (von Rueden \& Gurven, 2012; von Rueden et al., 2014). Hence, dominant individuals should be better able to successfully intervene in intragroup conflicts as leaders through face-to-face interactions with followers, and the needs for such interventions by dominant leaders should be given special priority during periods of heightened intra- or inter-group conflict (von Rueden \& van Vugt, 2015, 6; Laustsen \& Petersen, 2015). In modern societies, people experience structurally similar problems of horizontal exploitation in terms of criminal activity, welfare recipients disincentivized to find work, or tax and benefit fraudproblems that people look to leaders to solve (Davey, 1998; Cummins, 2009). As a result, we expect that contexts in which such problems of horizontal exploitation are salient will automatically instill a dominant leader prototype in the minds of followers and increase preferences for a dominant leader.

Importantly, though, individuals would not only have faced risks of exploitation from other rankand-file group members. A fundamentally different kind of exploitation originates from group leaders themselves. We will refer to this as vertical exploitation as it originates from group leaders 
abusing their privileged hierarchical position to acquire resources for themselves or their immediate relatives and allies at the expense of rank-and-file group members. This kind of leader exploitation - also referred to as alpha-type "bullying behavior"—is believed to have molded human morality and given rise to general human preferences for egalitarianism and dislikes of too much hierarchy (Boehm, 1999; Van Vugt \& Ahuja, 2011; von Rueden \& van Vugt, 2015; Bøggild $\&$ Petersen, 2015). Thus, vertical exploitation problems should have been of major importance throughout human evolutionary history, and based on this we expect that a specific prototype is also devoted to contexts associated with high risks of exploitation by leaders. Specifically, we predict that contexts associated with risks of vertical exploitation should — in contrast to horizontal exploitation contexts - call for a non-dominant group leader. While dominance should signal competence in dealing with problems related to horizontal exploitation (and warfare, e.g., Little et al., 2007; von Rueden \& van Vugt, 2015), it is also associated with self-assertiveness and selfinterested, anti-social behavior implying that dominant individuals are also more inclined to act upon opportunities to engage in exploitation (Mazur \& Booth, 1998; Stirrat \& Perrett, 2010; von Rueden et al., 2014). In a modern context, followers also face similar risks of vertical exploitation in terms of leaders' careerism, affiliation with special interests, and sometimes even illegal activities and corruption (Hibbing \& Theiss-Morse, 2002; Bowler \& Karp, 2004; Bøggild, forthcoming). Consequently, we expect that contexts characterized by high risks of vertical exploitation will increase preferences for a non-dominant leader.

In sum, we expect horizontal exploitation contexts and vertical exploitation contexts to be associated with two very different leader prototypes: A dominant and a non-dominant prototype, respectively. Therefore, these two types of exploitation — calling for opposite qualities in a group leader - confront followers with a dilemma in which they must trade off leader traits according to the immediate relative salience of horizontal and vertical exploitation. As a result, we should expect 
an evolved followership psychology to take in contextual information about risks of horizontal and vertical exploitation, weigh these risks against each other, and ultimately produce leader preferences that match a given context. When risks of horizontal exploitation outweigh risks of vertical exploitation, people should opt for a relatively more dominant leader with the motivations and capabilities to effectively restore social order through punitive enforcements. In contrast, when risks of vertical exploitation outweigh risks of horizontal exploitation, people should prefer a relatively less dominant leader who is less motivated to engage (and capable of engaging) in self-interested behavior at the expense of followers. This gives rise to our first hypothesis:

H1: Followers will prefer more dominant leaders in horizontal exploitation contexts compared to vertical exploitation contexts.

\section{Coalitions, exploitation, and ethnicity}

Another implication of our basic argument (that preferences for leader dominance vary by risks of exploitation posed by others within the group) is that followers should also adjust their preferences for leader dominance according to the coalitional belonging of potential leaders. Specifically, the follower should be attuned to whether risks of vertical exploitation are more likely to be directed towards her than towards fellow followers. That is, a follower's preferences for leader dominance should also depend on whether the leader is perceived as likely to consider and respect the welfare of the follower or is more likely to act upon opportunities of vertical exploitation against the follower. One important way in which people infer if others are likely to consider their welfare or pose a risk of exploitation is according to their coalitional belonging. A number of studies demonstrate that individuals from the same coalition are more likely to engage in reciprocal relations with each other and give preferential treatment to individuals who in some way share their 
coalitional belonging — for example in terms of clothing, dialect, or ethnicity (e.g., Sherif, Harvey, Hood, Sherif, \& White, 1988; Habyarimana, Humphreys, Posner, \& Weinstein, 2007; Efferson, Lalive, \& Fehr, 2008). Consequently, clarifying if coalitional belonging is shared with another individual from the group holds important information about future exchanges and welfare considerations (Nettle \& Dunbar, 1997; Cohen, 2012). Psychological research demonstrates that people are equipped with a coalitional psychology that automatically categorizes another individual according to coalitional markers. This allows them to determine the likelihood of this individual caring about their welfare and engaging in exploitation against them (Kurzban, Tooby, \& Cosmides, 2001; Cosmides, Tooby, \& Kurzban, 2003; Pietraszewski, Cosmides, \& Tooby, 2014; Pietraszewski et al., 2015). We argue that the same basic mechanisms are employed when followers evaluate potential leaders. Specifically, exploitation on the part of a leader should be feared more among rank-and-file group members who do not share the leader's coalitional belonging. Representing a certain intra-group coalition, the leader is more dependent upon the support from individuals sharing this belonging than the support from followers from a different coalition. Therefore, the leader should be more protective of the welfare of followers from her own coalition and direct potential exploitative efforts against followers from different coalitions whose support is less valuable.

In this article, we focus on ethnicity as a coalitional marker for two reasons. First, it is well established that the coalitional psychology automatically categorizes others according to ethnicity and that people often show favoritism towards members of their own ethnic coalition (Bobo, 1983; Kurzban, Tooby, \& Cosmides, 2001; Cosmides, Tooby, \& Kurzban, 2003; Habyarimana et al., 2007). Second, ethnicity comprises a salient political marker in most western democracies as illustrated by the general interest in ethnically based voting and ethnic minority candidates (e.g., Hutchings \& Valentino, 2004). Moreover, ethnicity and immigration constitute defining political 
issues with ethnic cleavages and perceptions permeating and structuring public opinion on key policy issues including welfare, crime, and redistribution (Bobo, 1983; Alesina, Glaeser, \& Sacerdote, 2001; Alesina \& Glaeser, 2006). Based on this, we believe ethnicity serves as a salient coalitional marker to modern voters and followers.

Some evidence supporting this idea already exists. One study finds that "babyfacedness"—a trait closely associated with non-dominance - is a negative predictor of success for white CEOs but is positively associated with success among black CEOs (Livingston \& Pearce, 2009). This leads Van Vugt \& Grabo $(2015,7)$ to speculate that "[f]ollowers may only prefer leaders from a different ethnic background if they have a particularly trustworthy [non-dominant and babyish] face." Hence, the ethnic belonging of a potential leader should be an important factor in determining if this individual would be inclined to engage in vertical exploitation against the self and, in turn, influence preferences for leader dominance. This leads to our second hypothesis:

H2: Followers will prefer less dominant leaders when they choose among candidates from a different ethnic coalition than among candidates from their own ethnic coalition.

Of course, a potential tendency for followers to prefer less dominant leaders when choosing among individuals from a different ethnic coalition could have many causes. How can we know if this tendency is in fact driven by differences in perceived risks of intra-group exploitation on the part of ethnically different and ethnically similar group leaders (as our main argument implies)? If the theoretical mechanism we propose is correct, we should expect an increase in followers' tendency to prefer leaders from different ethnic coalitions to be less dominant when they face contexts characterized by vertical exploitation. In other words, if our suggested mechanism is correct, we should expect an interaction between leaders' coalitional belonging and contextual 
information. Specifically, a potential leader's ethnic (and thus, coalitional) belonging should be of major importance to a follower when the contextual risk of vertical exploitation is high because it is vital in determining if such exploitation is likely to be targeted at the self or at other group members. In contrast, when the risk of horizontal exploitation is high the prime objective for followers should be to look for a leader with the motivation and ability to punitively enforce collective action and uphold social order (i.e., a dominant leader). In such contexts, cues concerning the distribution of costs of vertical exploitation (such as leader ethnicity) should be less important. This leads to our third and final hypothesis:

H3: The tendency for followers to prefer less dominant leaders when choosing among candidates from a different ethnic coalition is stronger in vertical compared to horizontal exploitation contexts.

\section{Overview of studies and procedure}

To test our three predictions, we conducted four separate studies and pilot tests of the materials used in the studies. To obtain valid measures of preferences for leader dominance, we rely both on computer generated faces used in existing work (e.g., Little et al., 2007; Spisak et al., 2012a, 2012b; Laustsen \& Petersen, 2015, 2016) and construct new facial materials based on manipulations of real political candidates' faces. Studies 1, 2, and 3 test $\mathrm{H} 1$ on diverse samples of American subjects recruited through Amazon Mechanical Turk (MTurk) (Studies 1 and 2) and a nationally representative sample of Danish citizens (Study 3). These studies employ different operationalizations of leader dominance and the key contextual distinction between horizontal and vertical exploitation in order to replicate and strengthen the internal validity of our findings. Next, Study 4 aims to replicate and extend these findings by simultaneously testing $\mathrm{H} 1, \mathrm{H} 2$, and $\mathrm{H} 3$ with a sample recruited through MTurk. Across Studies 1-4 we report the results from the pilot tests- 
conducted with American subjects - to establish the validity of our applied materials before they are used to test the hypotheses.

The studies were conducted in both Denmark and the United States in order to strengthen the universality of our central theoretical claim in two fundamentally different, modern democracies. Thus, similar findings from experiments conducted in the vastly different institutional and cultural settings of Denmark and the United States (see e.g., Nelson \& Shavitt, 2002) will strengthen the generalizability of the findings and support the theoretical account stressing an evolved, universal followership psychology. Before we present the studies, we consider a caveat following from the experimental procedure applied in previous studies and discuss how this concern is alleviated in this article.

The experimental procedure used in most existing work is to randomly assign subjects to vignettes of inter-group war or peace, respectively, and afterwards present them with the choice between two versions of the same leader face varying only according to facial dominance (e.g., Little et al., 2007; Spisak et al. 2012a; Laustsen \& Petersen 2015). This approach, however, introduces the risk of demand effects since subjects might easily see through the purpose of the study and what the researchers consider the "correct" response in terms of the strong, dominantlooking individual in the context of war or the softer, non-dominant individual in the context of peace. In this article, we add to this literature not only by introducing an intra-group perspective (as laid out in the theory section above) but also by employing alternative experimental procedures when studying followers' preferences for leader dominance. Especially, the design applied in Study 2 alleviates concerns about demand effects with only one face evaluated under a given contextual condition per subject. 
Before presenting our four studies, we describe the specific procedures used to create the visual materials for the studies and clarify how these procedures depart from and extend previous work on face-based leader preferences.

\section{Candidate faces and morphing procedures}

As mentioned above, we measure preferences for leader dominance by having subjects rate and choose between different faces of potential leaders that are manipulated to vary with respect to perceived dominance. Facial dominance is found to relate closely to facial cues of physical strength and masculinity such that faces with squarer jaws, smaller eyes, thicker, lowered and "bushier" eyebrows, thinner lips, and larger facial width-to-height ratios are perceived as more dominant (Carré, McCormick, \& Mondloch, 2009; Keating \& Bai, 1986; Sell et al., 2009; Zilioli et al., 2014). Importantly, existing work has demonstrated that people - even children down to the age of 3 instinctively categorize others according to such dominance features (Keating \& Bai, 1986; Cogsdill et al., 2014) and that such perceptions of dominance reliably predict real-life dominant behaviors such as aggressiveness and anger (Carré \& McCormick, 2008; Carré et al., 2009), combat skills and success (Třebický et al., 2013; Zilioli et al., 2014), and self-interested attitudes and behavior (Sell et al., 2009; Stirrat \& Perrett, 2010).

In Study 1, we follow previous research (e.g., Little et al. 2007) and rely on computer-generated faces from an open access online face database (for more information about database see Oosterhof $\&$ Todorov, 2008). From this database, we chose three different baseline faces and compiled the " +3 " and " -3 " standard deviation versions of each face. Using the face manipulation software Psycho Morph, we made an average dominant face from the " +3 " versions of the faces and an average non-dominant face from the "-3" versions of the same baseline faces (for information about 
Psycho Morph, see Tiddeman, Stirrat, \& Perrett, 2005). The two average faces are shown in panel a, Figure 1.

For studies 2, 3, and 4, we substituted these somewhat artificially looking faces with morphed versions of real-life political candidates. Specifically, we compiled eight photos of real-world politicians from Scandinavia and used the morphing software Psycho Morph to create different versions of each politician's face varying on facial dominance. To vary candidate ethnicity (for investigations of $\mathrm{H} 2$ and $\mathrm{H} 3$ ) in Study 4, four of the eight politicians were chosen from the Norwegian parliament and had Scandinavian origins, representing the same ethnic coalition as our subjects. The remaining four politicians were also elected representatives in Norway, Denmark, or Sweden but were first- or second-generation immigrants from Iran, Syria, Pakistan, or Turkey (Middle Eastern and Eastern countries), representing an ethnic coalition different from that of our subjects. For simplicity, we refer to these two groups as ethnically similar candidates and ethnically different candidates, respectively (details on the visual materials for ethnically similar and ethnically different candidates are presented in Study 4).

These eight candidate photos were morphed with respect to facial dominance following a standard procedure: Based on the original photo of each candidate, we made a scale of seven photos in which only the facial dominance of the target politician varied. Using the morphing software Psycho Morph, we loaded and changed each target politician's face into seven different versions along a facial dominance dimension. To morph the different versions of the eight real-world politicians, we used the average dominant face and the average non-dominant face as opposite anchors (displayed in panel a, Figure 1). Based on this, each of the eight candidate photos was morphed $15 \%, 30 \%$ and $45 \%$ in direction of the average dominant face yielding the $+15,+30$ and +45 facial dominance versions of each candidate face. Likewise, each of the candidate photos was 
morphed $15 \%, 30 \%$ and $45 \%$ in direction of the non-dominant anchor yielding the $-15,-30$ and -45 facial dominance versions of each candidate face (Tiddeman et al., 2005).

\section{FIGURE 1 ABOUT HERE}

Figure 1 provides examples of the materials applied across our four studies. Specifically, Figure 1 displays the full scale of seven faces from the least dominant version (-45) to the most dominant version (+45) for one of the ethnically similar candidates in panel b (Heikki Holmås) and one of the ethnically different candidates in panel c (Özkan Kocak). As mentioned above, we use the facial material in different ways across the four studies below to accommodate risks of demand effects and strengthen the internal validity of our findings.

\section{Study 1}

\section{Design and measures}

Study 1 was conducted on an American sample recruited through MTurk (N=177). The study was designed to test $\mathrm{H} 1$ and, thus, manipulated contextual information on horizontal and vertical exploitation. Specifically, subjects all read a common introduction in which they were asked to imagine an election of a new governor in their state. Next, they were assigned to one of two conditions describing the most salient problems facing their state and the future governor: 1) In the horizontal exploitation scenario, subjects were told that the state had been "facing serious problems with gang members who harass and exploit ordinary citizens and collect welfare benefits without contributing to society." 2) In the vertical exploitation scenario, subjects were told that the state had been "facing serious problems with corrupt governors who are unresponsive to the needs of 
ordinary citizens and exploit their power for personal gain.” Panel a, Figure 2 presents the full scenario descriptions.

\section{FIGURE 2 ABOUT HERE}

Subsequently, Study 1 followed previous work and presented subjects with two faces varying only on facial dominance (the average faces described above constructed based on an open access face database; see Oosterhof \& Todorov, 2008) and asked them to indicate which individual they would choose for the described job as governor. Panel b, Figure 2 presents the two faces used in Study 1. In this way, Study 1 implemented the procedure used hitherto when studying preferences for facial dominance in leaders in order to test if the intra-group perspective (horizontal versus vertical exploitation) introduced here yields results similar to what prior research investigating differences in inter-group contexts (war versus peace) have found. In this way, Study 1 adds an intra-group perspective to existing work using the traditional design before we move on and address the inherent risks of demand effects from this design in Study 2.

\section{Results}

We test $\mathrm{H} 1$ by comparing subjects' preferences for the facially dominant individual relative to the facially non-dominant individual across the horizontal and vertical exploitation scenarios. The analysis shows that $55 \%$ of the subjects choose the dominant-looking leader in the horizontal exploitation condition whereas only $31 \%$ choose the dominant-looking leader in the vertical exploitation condition. Hence, in support of $\mathrm{H} 1$ the experimental prime about risks of horizontal exploitation causes subjects to hold stronger preferences for dominant-looking governors than the corresponding prime about risks of vertical exploitation. This difference amounts to a significant 24 
percentage point effect $(\mathrm{t}=3.288, \mathrm{p}=0.001)$ and supports our basic argument that preferences for facial dominance in political candidates and leaders are sensitive to intra-group contextual differences concerning risks of horizontal and vertical exploitation.

\section{Study 2}

\section{Design and measures}

Study 2 was conducted on an American sample recruited through MTurk $(\mathrm{N}=391)$ and serves to replicate and extend the finding presented in Study 1. First, we wanted to substitute the slightly artificial-looking faces based on the open access face database with morphed versions of a real world politician. Second, we wanted to address a potential shortcoming in the design of Study 1 and previous studies on preferences for facial dominance in leaders. Specifically, the different preferences for candidate faces across contexts could be a result of demand effects. Because subjects are always presented with two faces varying on facial dominance, they might be able to see through the purpose of having them choose between a dominant and a non-dominant face. Consequently, they might choose the dominant, tough-looking candidate when assigned to a scenario of conflict and anarchy (such as horizontal exploitation or war contexts) not because they actually prefer the dominant face in such settings, but because they might infer that this is what the researcher wants them to choose. Similarly, they might choose the non-dominant, agreeable-looking candidate when assigned to a scenario of diplomacy and pro-social leadership (such as vertical exploitation or peace contexts), again, potentially because of inferred researcher intentions rather than real preferences. To remedy that the results from Study 1 were potentially caused by such demand effects, we randomly assigned subjects to evaluate only one face-a dominant or nondominant — after reading either the vertical or the horizontal exploitation scenario. In this way, Study 2 minimizes the risks of demand effects providing a clearer test of subjects' context sensitive 
leader preferences. Hence, Study 2 was a 2x2 factorial design in which subjects were randomly assigned to one of the contextual scenarios as in Study 1 (see panel a, Figure 2 for full descriptions) and to either a dominant (“+45") or a non-dominant ("-45") version of the Norwegian politician Heikki Holmås (depicted in Figure 3). Rather than choosing between two faces, subjects now answered "to what extent this politician looks like the right person for the job as governor" on a 11point scale which we recode from 0 (not at all right for the job) to 1 (very right for the job) scale. This allows us to investigate if the same face was perceived differently depending on the assigned contextual scenario of horizontal and vertical exploitation, respectively.

Before being assigned to any context or face in Study 2, subjects participated in a short rating study of the manipulated facial materials used in this study and additional facial material used in Studies 3 and 4 below. As expected, the dominant face used in Study 2 was perceived as more dominant looking than the used non-dominant face among our subjects $(\mathrm{p}<0.001$; and this pattern replicated in an additional, independent pilot study on MTurk $(\mathrm{N}=41){ }^{1}$

\section{FIGURE 3 ABOUT HERE}

\section{Results}

In the context of Study 2, H1 is supported if the dominant face is perceived as better for the job as governor in the horizontal exploitation scenario compared to the non-dominant face and if, vice versa, the non-dominant face is seen as better for the job as governor in the vertical exploitation scenario. That is, the key test of our argument in testing H1 is if a two-way interaction between face

\footnotetext{
${ }^{1}$ This rating exercise also served to familiarize the subjects with impression formation of individuals from facial appearances along relevant dimensions of trait perceptions. Importantly, this rating exercise did not prime subjects to associate certain traits with the contexts of vertical and horizontal exploitation, respectively, as the contexts were not introduced until after the rating exercise.
} 
(dominant vs. non-dominant) and context (horizontal exploitation vs. vertical exploitation) is significant.

Using OLS regression, we find strong support for this argument with a significant two-way interaction between face and context $(b=-0.23, p<0.001)$. Table 1 shows the full regression model for this analysis.

\section{TABLE 1 ABOUT HERE}

Importantly, a more nuanced analysis of the mean perceptions of "how right the person looks for the job as governor" for each of the four combinations of face and context reveals a pattern that strongly supports H1. Figure 4 illustrates the mean ratings for both the dominant and the nondominant candidate face within the horizontal exploitation context (left-hand side) and the vertical exploitation context (right-hand side), respectively. Among subjects assigned to the horizontal exploitation condition the dominant face is rated as looking significantly more right for the job than the non-dominant face $\left(\mathrm{M}_{\text {dominant }}=0.65, \mathrm{SD}=0.21 ; \mathrm{M}_{\text {non-dominant }}=0.50, \mathrm{SD}=0.20 ; \mathrm{t}=5.87, \mathrm{p}<\right.$ 0.001). Substantially, this corresponds to a difference of 15 percentage points in favor of the dominant face. In contrast, subjects assigned to the vertical exploitation scenario rate the nondominant face as looking significantly more right for the job as governor than the dominant face $\left(\mathrm{M}_{\text {non-dominant }}=0.58, \mathrm{SD}=0.16 ; \mathrm{M}_{\text {dominant }}=0.50, \mathrm{SD}=0.29 ; \mathrm{t}=2.71, \mathrm{p}=0.007\right)$. Substantially, this corresponds to a difference of 8 percentage points in favor of the non-dominant face. 
In sum, these results further strengthen the support for H1. Not only are dominant and nondominant versions of the same leader face rated differently under horizontal and vertical exploitation scenarios; the relative perceptions of the two faces also flip such that the face perceived as the better leader under horizontal exploitation risks (i.e., the dominant face) is not seen as the better leader under vertical exploitation risks. Rather, under this latter scenario the face that was seen as relatively worse under horizontal exploitation (i.e., the non-dominant face) is now perceived as better under vertical exploitation. This underlines that preferences for leader dominance are flexibly responding to changing contextual conditions of horizontal and vertical exploitation risks. Moreover, the design of this study accommodates the risk of demand effects in Study 1 and the existing literature. With this finding established, we turn to a test of our argument in a different cultural setting and using a wider set of morphed faces.

\section{Study 3}

\section{Design and measures}

Study 3 was conducted for two purposes. First, it aimed to replicate the support for H1 in a widely different institutional and cultural setting. To this end, the study was conducted on a nationally representative sample of Danish citizens recruited through the YouGov survey agency matching the general population on age, sex, education, and geographical location $(\mathrm{N}=312)$. As mentioned above (see "Overview of studies and procedure"), Denmark and the United States serve as two very different countries within the category of modern democracies. Therefore, reaching the same substantial conclusions across these countries will both strengthen the external validity of the findings and support the notion of an evolved — and as a consequence- - universal followership psychology. Since Denmark does not have governors, we randomly assigned subjects to one of two 
scenarios in which they were asked to imagine electing a mayor for their municipality (for the full scenario descriptions see Appendix A).

\section{FIGURE 5 ABOUT HERE}

The second purpose of Study 3 was to use facial material for multiple candidates and the full scale of our morphed facial materials. This allows us to test $\mathrm{H} 1$ using multiple real-life political candidates as target faces and to obtain a more nuanced and fine-grained measure of leader dominance by allowing subjects to choose between different degrees of facial dominance within the same target candidate. In Study 3, we randomly assigned subjects to either the horizontal or the vertical exploitation scenario. Next, all subjects performed four choices of their preferred candidate face (all within the same scenario). For each of these choices subjects were exposed to a "withinpolitician facial dominance scale" consisting of seven different versions of the same candidate face. Figure 5 depicts the four facial dominance scales used in Study 3 (for specific morphing procedures see the section "Candidate faces and morphing procedures"). The four different scales (the four candidates) were presented in random order, and for each scale subjects were asked to indicate "how the politician should look if you were to elect him for the described job as mayor." In the analyses, we recode each of the four scales such that " 0 " indicates that the subject has chosen the least dominant face, while " 1 " indicates a preference for the most dominant face.

To verify that the morphing procedures worked as expected, we conducted a pilot test on MTurk $(\mathrm{N}=41)$. For simplicity, we presented subjects with only the most dominant-looking (the " $+45 "$ versions) and the least dominant-looking (the “-45" versions) versions of the candidates' faces and asked them to indicate which version they perceived as the more dominant-looking. In support of our morphing procedure, the dominant version of a given face was consistently chosen as more 
dominant-looking than the non-dominant version across all four candidates ( $\mathrm{p}<0.001$ for all candidates). Hence, the applied morphing procedure translates into perceived differences in facial dominance among our subjects. Moreover, in a follow-up pilot test (embedded in the same survey as Study 2; $\mathrm{N}=395$ ) we verified (in line with previous work, e.g., Oosterhof \& Todorov, 2008; Olivola \& Todorov, 2010a; Laustsen \& Petersen, 2016) that the facially dominant versions were also consistently perceived as more physically strong, less trustworthy, and less agreeable (all differences significant with $\mathrm{p}<0.001)$.

In sum, all 312 subjects performed four candidate choices on the same four "within-politician facial dominance scales." Importantly, they performed all four choices after being assigned to either the horizontal exploitation context or the vertical exploitation context.

\section{Results}

To test H1 in the context of Study 3, we utilize that each subject performed four choices. That is, we have four observations per subject yielding a total of 1,248 observations. We analyze Study 3 using OLS regression and employ standard errors clustered at the subject level to take account of the four choices performed by each subject (choices nested in subject). Model 2.1 in Table 2 reports the effect of being assigned to the vertical exploitation scenario as opposed to the horizontal exploitation scenario. In strong support of $\mathrm{H} 1$, subjects choose a significantly less dominant looking candidate face when assigned to the vertical exploitation scenario as opposed to the horizontal exploitation scenario $(b=-0.121, p<0.001)$. Across the four choices, subjects assigned to the vertical exploitation scenario report a preferred facial dominance score of 0.409 , while subjects assigned to the horizontal exploitation context exhibit a preferred facial dominance score of 0.530 a difference of 12 percentage points. Importantly, we performed two different robustness analyses also controlling for potential candidate specific effects (see e.g., Antonakis, Bendahan, Jaquart, \& 
Lalive 2010). In model 2.2 in Table 2, we re-estimated the model adding a dummy variable for three of the four candidates (leaving candidate 1 out as reference category), which yielded the same substantial conclusion regarding H1 $(b=-0.121, p<0.001)$. Moreover, Model 2.2 also shows that subjects did differ somewhat in their preferences for facial dominance across candidates (as captured by the two significant candidate dummies). Finally, to make sure that the contextual effect was not driven by any particular candidate, we further included interaction terms between the contextual manipulation and each of the three candidate dummies in Model 2.3. Whereas the main effect of context remains unchanged and highly significant $(b=-0.125, p<0.001)$, we found no signs of significant interaction between the context and the candidate dummies $(\mathrm{F}(3,311)=1.03, \mathrm{p}$ $=0.380)$.

\section{TABLE 2 ABOUT HERE}

Together with the results from Study 1 and 2, these findings support H1 across three distinct experimental designs. The results from Study 1-3 also establish that intra-group contexts of exploitation affect follower preferences for dominance in leaders in similar ways in countries that differ markedly with respect to political institutions and broader culture. Building on these findings, Study 4 investigates if the ethnicity of political candidates and, thus, their coalitional belonging shape preferences for leader dominance and if this tendency increases with contextual risks of vertical exploitation. In other words, Study 4 adds candidate ethnicity to the experimental setup of Study 3 in order to test $\mathrm{H} 2$ and $\mathrm{H} 3$.

\section{Study 4}

\section{Design and measures}


Study 4 was conducted on American subjects through MTurk (N=808) and served to replicate and extend the findings presented above in two ways. First, to replicate the support for H1 we randomly assigned subjects to the horizontal or vertical exploitation scenarios used in Study 3 (for full scenario descriptions, see Appendix A). The only difference in the scenario descriptions from Study 3 was that subjects were asked - as in Study 1 and 2 - to imagine that they were to elect a new governor for their state rather than a new mayor for their municipality.

Second and more importantly, Study 4 also served to test H2 and H3. Following Study 3, subjects first read the assigned contextual scenario and were then asked to choose their favored candidate photo on four separate "within politician facial dominance scales" (corresponding to four different candidates). As in Study 3, these scales appeared in random order across subjects. Next, Study 4 departed from Study 3 in one central way. In Study 4 we also manipulated the coalitional belonging of the candidates through the use of two sets of "within politician facial dominance scales": One set consisting of four ethnically similar candidates (the same scales as used in Study 3 (see Figure 5)), and one set consisting of four ethnically different candidates (see Figure 6). Hence, the design of Study 4 consists of a between-subject 2 (horizontal vs. vertical exploitation scenario) by 2 (ethnically similar vs. ethnically different candidates) factorial design allowing for a test of $\mathrm{H} 1$, $\mathrm{H} 2$ and $\mathrm{H} 3$ in the same study.

\section{FIGURE 6 ABOUT HERE}

Importantly, to hold as many features as possible constant across the ethnically similar and ethnically different candidates, both groups were composed of middle-aged males not wearing glasses. Moreover, both the group of ethnically different and ethnically similar politicians consisted of candidates from across the ideological spectrum. To verify that the groups of ethnically similar 
and ethnically different candidates were comparable, we conducted a set of pilot tests on MTurk. In the first test $(\mathrm{N}=102)$, subjects rated the facial dominance of the original, un-morphed photos of all eight candidates on an 11-point scale which we recode to a $0-1$ scale (1 representing maximum facial dominance). This rating study showed no substantial differences between ethnically similar candidates $(M=0.574 ; S D=0.125)$ and ethnically different candidates $(M=0.614 ; S D=0.129)$. In the second test $(\mathrm{N}=79)$, we asked subjects about their perceptions of the ethnicity of the candidates and, thus, if subjects perceived the candidates to represent the same coalition as themselves. Since this test (and Study 4) was conducted with American subjects, they were asked: "Overall, to what extent would you say that the politicians just shown look American?" Answers were given on an 11-point scale ranging from "Not at all American" to "Very American" which we rescaled 0-1. As expected, the four ethnically similar candidates were found to look substantially more American than the four ethnically different candidates $\left(M_{\text {similar }}=0.949, S D=0.178 ; M_{\text {different }}=0.557, S D=\right.$ 0.267). That is, based on these two tests, the chosen sets of ethnically different and ethnically similar candidates seem highly similar in all other central aspects than their ethnic coalition. Third, following the tests applied for the ethnically similar candidates in Study 3, we verified (MTurk sample, $\mathrm{N}=38$ ) that the most dominant (" $+45 ")$ version of any of the four ethnically different candidates" face was also perceived as more dominant than the least dominant ("-45") version of the same face $(\mathrm{p}<0.01$ for all candidates $)$.

Finally, the pilot test used to establish the difference in perceived dominance between the most ("+45") and least ("-45") dominant version of each of the faces also asked subjects which of the two versions they would vote for. Subjects presented with the four ethnically similar candidates $(\mathrm{N}=$ 41) on average chose the dominant over the non-dominant version in $41.46 \%$ of the choices. Subjects assigned to the four ethnically different candidates $(\mathrm{N}=38)$ on average only chose the dominant over the non-dominant version in $28.38 \%$ of the choices. This is markedly lower than 
among subjects assigned to the ethnically similar candidates ( $t$-test for difference: $t=1.73, p=0.088$ ) and thus — tentatively—supports H2 and our argument that people's preferences for leader dominance are flexibly and strategically designed to avoid exploitation by other individuals within the group.

To ensure that the distinction between ethnically similar and ethnically different candidates was meaningful to subjects, we limited the analyses below to include only subjects who identified as white Americans $(\mathrm{N}=631)$. The reported results remain substantially similar and significant when analyzing the full sample. As in Study 3, we recode subjects' preferences for facial dominance to a $0-1$ scale on which " 0 " constitutes a preference for the least dominant face and " 1 " the most dominant face.

\section{Results}

We use OLS regression for analyzing Study 4 and employ standard errors clustered at the subject level to take account of the four choices performed by each subject (choices nested in subject). Altogether, Study 4 consists of four observations per subject yielding a total of 2,524 observations.

Context effect (H1): In support of $\mathrm{H} 1$ - and replicating results from Study 1-3 - we find that subjects assigned to the vertical exploitation context prefer significantly less dominant looking candidates than subjects assigned to the horizontal exploitation condition $(b=-0.084, p<0.001)$. On average, subjects assigned to the vertical exploitation condition prefer a facial dominance score of 0.445 , while subjects assigned to the horizontal exploitation condition exhibit a preferred facial dominance score of 0.528 - a difference of about 8 percentage points. This result is reported in Model 3.1 of Table 3. We further conducted robustness analyses with respect to the contextual effect. Model 3.2 in Table 3 controls for potential candidate-specific effects by including dummy variables for seven of the eight candidates (leaving candidate 1 out as reference category), which 
yield the same result regarding $\mathrm{H} 1(\mathrm{~b}=-0.084, \mathrm{p}<0.001)$. Moreover, Model 3.2 also shows that subjects differed somewhat in their preferences for facial dominance across candidates - as captured by the significant candidate dummies — which is expected based on $\mathrm{H} 2$. We return to this when analyzing the effect of candidate ethnicity below. Finally, to make sure that the contextual effect was not only present for one or a few of the candidates, we further interacted the contextual manipulation with each of the candidate dummies in Model 3.3. Whereas the main effect of context remained significant $(b=-0.071, p<0.05)$, we found no signs of significant interaction between the context and the candidate dummies $(F(7,630)=1.25, \mathrm{p}=0.272))$. However, Model 3.3 does show that the interaction with the context for each of the ethnically similar candidates (Candidate 2, 3 and 4) is positive, while it is negative for each of the ethnically different candidates (Candidate 5, 6, 7 and 8). We return to this observation when analyzing $\mathrm{H} 3$ and the interactive relationship between context and candidate ethnicity.

\section{TABLE 3 ABOUT HERE}

Ethnicity effect (H2): In support of $\mathrm{H} 2$, Model 3.1 shows that subjects assigned to choose among ethnically different candidates exhibit facial dominance preferences that are significantly lower than subjects choosing among ethnically similar candidates $(b=-0.068, \mathrm{p}<0.001)$. On average, this difference almost equals 7 percentage points. Because the ethnicity variable is operationalized by distinguishing between the four ethnically similar and the four ethnically different candidates, the candidate dummies are perfectly collinear with the ethnicity variable and, therefore, we cannot estimate the effect of candidate ethnicity and simultaneously control for candidate specific factors (by including separate candidate dummies). However, based on Model 3.2 and the candidate dummies we see that three of the four ethnically different candidates (candidates 5-8) are preferred 
to look less facially dominant (indicated by the negative coefficients) than is the reference candidate (the ethnically similar candidate, candidate 1). Only Candidate 8 stands out (with a positive coefficient). In contrast, the rest of the ethnically similar candidates (candidates 2-4) are preferred to look more dominant than is candidate 1 (as indicated by the positive coefficients). This yields some further support for $\mathrm{H} 2$ as the tendency for subjects to prefer ethnically different candidates to look less dominant than ethnically similar candidates is not driven by one ethnically different candidate in particular. We return to this point when also investigating the robustness of the analyses for $\mathrm{H} 3$ below.

Context and ethnicity interaction (H3): In the theory section, we argued that people prefer ethnically different candidates to look less dominant than ethnically similar candidates because the former constitute a greater risk of vertical exploitation directed at the self. To tease out this mechanism, we test if context (horizontal versus vertical exploitation) interacts with candidate ethnicity (ethnically similar versus ethnically different). In support of H3, we find a significant interaction between context and candidate ethnicity $(b=-0.067, p=0.046)$. Model 3.4 in Table 3 reports this analysis. To get a more nuanced understanding of this interactive relationship Panel a, Figure 7 displays average levels of preferred facial dominance for subjects depending on assigned context and candidate ethnicity.

\section{FIGURE 7 ABOUT HERE}

Panel a, Figure 7 shows that for subjects assigned to the horizontal exploitation scenario, preferences for leader dominance do not vary according to leader ethnicity. Within the horizontal condition, subjects assigned to choose among ethnically similar candidates prefer a facial dominance score of 0.544 , while subjects choosing among ethnically different candidates prefer a 
facial dominance score of 0.510 - a difference that is not statistical significant $(b=-0.034, p=$ 0.171). However, within the vertical exploitation scenario - in which subjects are primed with the risks of leader exploitation —we get a very different result: Subjects assigned to choose among ethnically similar candidates prefer a facial dominance score of 0.492 , while subjects choosing among ethnically different candidates prefer a substantially and significantly lower facial dominance score of $0.391(b=-0.101, p<0.001)$. In other words, when confronted with risks of exploitation from other group members, subjects do not discriminate in their dominance preferences across ethnically similar and different candidates. However, when the risks of exploitation stem from the leader (i.e. the vertical exploitation condition) there is a significant 10 percentage point difference in preferences for facial dominance in leaders between ethnically similar and ethnically different candidates. Hence, leader ethnicity becomes more important when we move from the horizontal to the vertical exploitation scenario.

Next, we conducted a series of robustness analyses with respect to $\mathrm{H} 2$ and $\mathrm{H} 3$. These analyses are all estimated from Model 3.3 in which we interact each of the candidate dummies (rather than the candidate ethnicity variable) with the assigned contextual condition. Importantly for these analyses, Candidate 1-4 constitute the ethnically similar candidates, whereas Candidate 5-8 are the ethnically different candidates. Based on Model 3.3, we can test if the ethnicity effect is larger in the vertical exploitation condition compared to the horizontal exploitation condition (as expected in H3) while including candidate dummies and — as a consequence — account for any differences between the ethnically similar candidates and between the ethnically different candidates. First, within the horizontal exploitation context we find an average preferred facial dominance score of 0.544 and 0.510 for ethnically similar and ethnically different candidates, respectively, and this difference is not significant $(\mathrm{F}(1,630)=1.88, \mathrm{p}=0.170)$. On the contrary, within the vertical exploitation context, we find that the average preferred facial dominance score for ethnically similar 
candidates is 0.492 , while it is only 0.391 for ethnically different candidates, and this difference is strongly significant $(F(1,630)=19.28, \mathrm{p}<0.001)$. That is, we reach the same conclusions regarding H3 when including candidate dummies based on Model 3.3 as for Model 3.4.

Finally, to display our results graphically, Panel b in Figure 7 plots the average preferred facial dominance scores across the horizontal and vertical exploitation conditions for each of the eight candidates in Study 4. With respect to H1, the figure neatly shows how a more dominant face is always preferred in the horizontal compared to the vertical exploitation condition for each of the eight candidates. Regarding H2, the ethnically similar candidates (candidates 1-4 to the left in the figure) are generally preferred to look more dominant than the ethnically different candidates (candidates 5-8 to the right in the figure). However, it is noteworthy that candidate 8 does not quite conform to our expectation in $\mathrm{H} 2$ since our subjects prefer this candidate to look roughly as dominant as the ethnically similar candidates. Likewise, candidate 1 is preferred to look less dominant than some of the ethnically different candidates. Still, on average — and as also tested formally above — ethnically different candidates are generally preferred to look less dominant than ethnically similar candidates. Finally, regarding H3, Panel b, Figure 7 clearly shows how the contextual effect is larger for the ethnically different candidates (candidates 5-8) compared to their ethnically similar counterparts (candidates 1-4) as also shown by the significant interaction in Model 3.4.

In sum, Study 4 allows us to draw three conclusions. First, it replicates the findings from the studies above supporting $\mathrm{H} 1$ that followers prefer more dominant leader faces under horizontal exploitation contexts than under vertical exploitation contexts. Second, the results support $\mathrm{H} 2$ that followers prefer ethnically different candidates to look less dominant than ethnically similar candidates. And third, in line with H3, Study 4 shows that this effect is in fact driven by enhanced concerns about vertical (i.e., leader) exploitation posed by ethnically different candidates. All three 
findings support our general argument that preferences for candidate dominance are responsive to the perceived risks of exploitation by other individuals within one's own group.

\section{Discussion}

In this article, we build on evolutionary psychological theory and argue that leader preferences are flexibly and strategically designed to protect the individual from risks of exploitation from other individuals within the group. Specifically, we show that preferences for leader facial dominance are shaped by 1) contextual risks of free-riding and criminal behavior by other group members (i.e., horizontal exploitation) and unresponsive and self-interested behavior by leaders themselves (i.e., vertical exploitation), and 2) the ethnicity of a potential leader. Below we attend to the theoretical and practical implications of our findings and finally we point out directions for future research.

\section{Theoretical implications}

At the theoretical level, our findings are important in three ways. First, the article adds to the discussion on the usefulness and rationality of face-based leader choice and voting. While some scholars have argued that attending to physical features when choosing leaders is largely an inaccurate and shallow form of decision-making (Todorov et al., 2005; Lenz \& Lawson, 2011; Olivola \& Todorov, 2010b), this article suggests (along with other studies, e.g., Little et al., 2007; Laustsen \& Petersen, 2015, 2016) that visually based voting follows a systematic pattern and is sensitive to the nature of different problems facing one's group and society. Facial dominance is closely related to hormonal balances such as testosterone levels and, thus, aggressiveness and conflict-seeking behavior (Mazur \& Booth, 1998; Penton-Voak \& Chen, 2004; Carré \& McCormick, 2008). Such leader characteristics could be useful when confronted with free-riding, criminal behavior or inter-group conflict, pointing to a certain — if simplified — rationale for face- 
based leader choice. On the other hand, one can legitimately question if such characteristics are in fact helpful for modern-day leaders such as mayors or governors in fighting crime or reducing freeriding in society. The evolutionary perspective implies that our leadership psychology could be functioning according to an ancestral, small-scale logic. As a consequence it could be mismatched and not necessarily well adapted to navigating in modern contexts of mass politics or large-scale companies (see also Van Vugt et al., 2008; von Rueden \& van Vugt, 2015).

Second, to the best of our knowledge this is the first study to consider how the dynamics and effects of face-based voting can vary across candidates with different ethnicities. Our findings suggest that the disadvantages facing ethnic minority candidates could stem from them being associated with greater risks of vertical exploitation and self-interested behavior among majority individuals. This interpretation is consistent with extant work showing that non-dominant, babyfaced traits are negatively associated with leadership success among white CEOs but positively among black CEOs (Livingston \& Pearce, 2009). Moreover, the findings suggest that ethnic markers may not always be an important factor in leader choice but are relevant mainly when risks of vertical exploitation are present in the minds of ethnic majority voters. For example, in contexts calling for a dominant candidate to protect society against outside threats or deviant, norm-violating behavior from within society, candidate ethnicity may play a small role for candidate evaluations and choice.

Third, we want to stress that although we have built on evolutionary insights on followership and coalitional psychology, our results are also consistent with other theoretical perspectives on leadership such as implicit leadership theory or contingency models of leadership. Importantly, we consider these different perspectives to be supplementary rather than competing theoretical models. We believe that the evolutionary approach aligns the findings with existing work on visual appearance effects for political as well as non-political leaders (Little et al., 2007; Spisak et al., 
2012a, 2012b; Olivola et al., 2014; Laustsen \& Petersen, 20152016). In this way, the findings add to existing knowledge on the psychological foundations of leader preferences and followership decisions in a broad as well as in a more narrow political sense.

\section{Practical implications}

At the practical level, our findings are important in two ways. First, our findings add new insights on how to deal with the underrepresentation of (ethnic) minorities in leadership positions. Although the categorization of others as coalitional allies or competitors is a highly automatic and unconscious process, existing work shows that coalitional markers such as ethnicity can be overridden by other, even entirely artificial, markers such as shared affiliations with a sports team or shared interests in leisure activities (Kurzan, Cosmides, \& Tooby 2001). This points to a need to cultivate and highlight shared coalitional belongings among leaders and followers to reduce potential counter-productive inferences about a leader's exploitative intentions made by followers belonging to a different ethnic group. For example, such undesirable consequences of crossethnicity leader-follower relations might be alleviated by emphasizing common organizational, professional, or social identities. Second, our results further stress the conditions under which ethnic minority political candidates could potentially suffer the most from their minority status: When vertical exploitation and distrust in politicians are more pronounced. Based on this, ethnic minority candidates could benefit from seeking out districts and elections characterized as little as possible by these features. Finally, if ethnic candidates face such situations they should be aware of the need for them to send even stronger signals of non-dominance and trustworthiness than their ethnic majority rivals.

\section{Limitations and future research}


Some concerns about the generalizability of our findings are worth mentioning. First, while the article reports results from two culturally different countries (Denmark and the US) the effects of leader ethnicity were tested only in the American context. One might suspect that the same results would not be found in more ethnically homogenous societies (such as the Danish) where ethnic divisions are less salient. On the other hand, the ethnic diversity and higher frequency of ethnic minority politicians in the US could also dampen voters' reservations with or mistrust against candidates belonging to other ethnic groups. As demonstrated across a range of studies, high levels of contact and interaction between individuals from different ethnic groups often reduce hostility and negative stereotypes and induce empathy and tolerance (see Pettigrew \& Tropp, 2006 for a meta-analysis). This implies that effects of candidate ethnicity on preferences for candidate dominance could be stronger in more ethnically homogenous countries like Denmark. Moreover, due to the composition of our samples, the analyses are confined to ethnic majority voters, and it remains to be seen if the same effects apply among minority groups. Also, ethnic stereotypes might play an important role implying a need for comparing candidates from more than just two ethnic groups. Related to this, future studies could also incorporate alternative designs to what we employed here for testing different preferences for dominance in leaders across ethnicities. For instance, one could visually manipulate the ethnic characteristics of a target face using the software we applied for manipulating facial dominance, and then randomly assign subjects to evaluate the target leader (high/low in visual ethnic characteristics) under vertical and horizontal exploitation contexts.

Second, our studies only presented subjects with male leaders and it remains to be seen if our findings apply to preferences for female leaders. In ancestral groups male leadership has been the norm (von Rueden \& van Vugt, 2015), which could suggest that no- or less clear- evolved leader prototypes exist for female leaders. Or, female leaders may have been preferred to solve entirely 
different adaptive problems that would require, for example, high levels of empathy or coordination skills (see also Van Vugt, Hogan, \& Kaiser 2008). Hence, preferences for female leaders could represent a scope condition for our argument, and future research should address which specific traits are preferred in female leader candidates and under which conditions.

Third, another intriguing avenue for further research would be to investigate if preferences for leader dominance vary according to individual differences in whether followers themselves are likely to engage in horizontal or vertical exploitation against others. For example, would a follower engaging in criminal activity against others (i.e., horizontal exploitation) strategically opt for a nondominant leader to be able to keep up such exploitative efforts? This suggests that there might also be important individual-level differences in the ways horizontal and vertical exploitation shape leader preferences.

Fourth, our experimental approach provides a somewhat simplified test by priming subjects with either horizontal or vertical exploitation. This approach leaves open the question of how people respond when both (or neither) risks are salient and how exactly they weigh and trade off these two types of exploitation. It also leaves open the question of how followers react when both inter-group problems (i.e., war or peace) and intra-group problems (e.g., horizontal and vertical exploitation) are present. Does one type of problem take priority over the other? Do they yield additive effects so that, for example, contexts of war and horizontal exploitation each increase preferences for leader dominance, or do they interact and increase preferences for dominance exponentially? Our main focus in this article has been to add an intra-group perspective to the literature on preferences for leader (facial) traits, and we believe an important next step is to investigate how followers respond when they have to incorporate multiple — and possibly conflicting—problems and motivations in their choice of leaders. Such a multi-problem approach, we expect, holds the potential to explain 
variation in leader preferences and advance our understanding of the complex relationship between leaders and followers.

\section{Conclusions}

Our article shows that followers adjust their preference for leader dominance according to risks of exploitation posed by others within their group. People prefer more dominant-looking leaders in contexts characterized by risks of free-riding and criminal activities from other group members (i.e., horizontal exploitation). In contrast, they prefer less dominant-looking leaders in contexts characterized by risks of unresponsive, self-interested behaviors from the leaders themselves (i.e., vertical exploitation). In addition, followers prefer leaders representing another vis-à-vis their own ethnic coalition to look less dominant and this effect is driven by enhanced concerns for vertical exploitation from ethnically different leaders. The findings advance our understanding of the logics and dynamics underlying appearance-based leader choice and voting and have theoretical and practical implications for overcoming the underrepresentation of minorities in leadership positions. Our results call for future research on the interactive relationship between contextual factors and coalitional belongings of followers and leaders in shaping follower leader preferences.

\section{Acknowledgments}

The authors wish to acknowledge the helpful guidance and advice from Kevin Arceneaux, Peter DeScioli, Leonie Huddy, Michael Bang Petersen, Rune Slothuus, Kim Sønderskov, the section on political behavior and institutions at Department of Political Science, Aarhus University, Editor John Antonakis, and two anonymous referees. 


\section{References}

Alesina, A., \& Glaeser, E. (2006). Fighting Poverty in the US and Europe: A World of Difference. Oxford: Oxford University Press.

Alesina, A., Glaeser, E., \& Sacerdote, B. (2001). Why doesn't the United States have a Europeanstyle welfare state? Brookings Papers on Economic Activity, 2, 187-247.

Antonakis, J., \& Dalgas, O. (2009). Predicting elections: Child's play! Science, 323 (5918), 11831183. doi:10.1126/science. 1167748 .

Antonakis, J., Bendahan, S., Jacquart, P., \& Lalive, R. (2010). On making causal claims: A review and recommendations. The Leadership Quarterly, 21, 1086-1120.

Bobo, L. (1983). Whites' opposition to busing: Symbolic racism or realistic group conflict? Journal of Personality and Social Psychology, 45, 1196-1210. doi:10.1037/0022-3514.45.6.1196.

Boehm, C. (1999). Hierarchy in the forest: The evolution of egalitarian behavior. Harvard University Press.

Bøggild, T. (forthcoming). How politicians’ reelection efforts can reduce public trust, electoral support, and policy approval. Political Psychology

Bøggild, T., \& Petersen, M. (2015). The evolved functions of procedural fairness: An adaptation for politics. In T. Shackelford \& R. Hansen (Eds), The evolution of morality (pp. 247-276). New York: Springer.

Bowler, S., \& Karp, J.A. (2004). Politicians, scandals, and trust in government. Political Behavior, $26,271-287$.

Carré, J.M., \& McCormick, C.M. (2008). In your face: Facial metrics predict aggressive behaviour in the laboratory and in varsity and professional hockey players. Proceedings. Biological Sciences / The Royal Society, 275, 2651-2656. doi:10.1098/rspb.2008.0873. 
Carré, J.M., McCormick, C.M., \& Mondloch, C.J. (2009). Facial structure is a reliable cue of aggressive behavior. Psychological Science, 20, 1194-98. doi:10.1111/j.14679280.2009.02423.x.

Cogsdill, E.J., Todorov, A.T., Spelke, E.S., \& Banaji, M.R. (2014). Inferring character from faces: A developmental study. Psychological Science, 25, 1132-1139. doi:10.1177/0956797614523297.

Cohen, E. (2012). The evolution of tag-based cooperation in humans: The case for accent. Current Anthropology, 53, 588-616.

Cosmides, L., \& Tooby, J. (2005). Neurocognitive adaptations designed for social exchange. In Handbook of Evolutionary Psychology (pp. 584-627). Hoboken, NJ: Wiley.

Cosmides, L., Tooby, J., \& Kurzban, R. (2003). Perceptions of race. Trends in Cognitive Sciences, 7, 173-179.

Cummins, J. (2009). Issue voting and crime in gubernatorial elections. Social Science Quarterly, 90, 632-651. doi:10.1111/j.1540-6237.2009.00635.x.

Davey, J.D. (1998). The politics of prison expansion: Winning elections by waging war on crime. Greenwood Publishing Group.

De Cremer, D., \& Van Vugt, M. (2002). Intergroup and intragroup aspects of leadership in social dilemmas: A relational model of cooperation. Journal of Experimental Social Psychology, 38, 126-136. doi:10.1006/jesp.2001.1499.

De Waal, F.B.M. (1997). Good natured: The origins of right and wrong in humans and other animals. Cambridge: Harvard University Press.

Efferson, C., Lalive, R., \& Fehr, E. (2008). The coevolution of cultural groups and ingroup favoritism. Science, 321, 1844-1849. doi:10.1126/science.1155805. 
Fiedler, F. (1964). A contingency model of leadership effectiveness. In L. Berkowicz (Ed.), Advances in Experimental Social Psychology (pp. 149-190). New York: Academic Press.

Flack, J.C., Girvan, M., de Waal, F.B.M., \& Krakauer, D.C. (2006). Policing stabilizes construction of social niches in primates. Nature, 439, 426-429. doi:10.1038/nature04326.

Funk, C.L. (1999). Bringing the candidate into models of candidate evaluation. The Journal of Politics, 61, 700-720. doi:10.2307/2647824.

Habyarimana, J., Humphreys, M., Posner, D.N., \& Weinstein, J.M. (2007). Why does ethnic diversity undermine public goods provision? American Political Science Review, 101, 709725. doi:10.1017/S0003055407070499.

Hall, C., Goren, A., Chaiken, S., \& Todorov, S. (2009). Shallow cues with deep effects: Trait judgments from faces and voting decisions. In The Political Psychology of Democratic Citizenship (pp. 73-99). New York: Oxford University Press.

Hayes, D. (2005). Candidate qualities through a partisan lens: A theory of trait ownership. American Journal of Political Science, 49, 908-923.

Hibbing, J.R., \& Theiss-Morse, E. (2002). Stealth democracy: Americans' beliefs about how government should work. Cambridge University Press.

Hutchings, V.L., \& Valentino, N.A. (2004). The centrality of race in American politics. Annual Review of Political Science, 7, 383-408. doi:10.1146/annurev.polisci.7.012003.104859.

Kaplan, H., \& Gurven, M. (2005). The natural history of human food sharing and cooperation: A review and a new multi-individual approach to the negotiation of norms. In H. Gintis, S. Bowles, R. Boyd, \& E. Fehr (Eds), Moral sentiments and material interests: On the foundations of cooperation in economic life (pp. 75-113). Cambridge: MIT Press.

Keating, C.F., \& Bai, D.L. (1986). Children's attributions of social dominance from facial cues. Child Development, 57, 1269-1276. doi:10.2307/1130449. 
King, A.J., Johnson, D.D.P., \& Van Vugt, M. (2009). The origins and evolution of leadership. Current Biology, 19, R911-16. doi:10.1016/j.cub.2009.07.027.

Kurzban, R., Tooby, J., \& Cosmides, L. (2001). Can race be erased? Coalitional computation and social categorization. Proceedings of the National Academy of Sciences of the United States of America, 98, 15387-15392. doi:10.1073/pnas.251541498.

Laustsen, L., \& Petersen, M.B. (2015). Does a competent leader make a good friend? Conflict, ideology and the psychologies of friendship and followership. Evolution and Human Behavior, 36, 286-93. doi:10.1016/j.evolhumbehav.2015.01.001.

Laustsen, L., \& Petersen, M.B. (2016). Winning faces vary by ideology: How non-verbal source cues influence election and communication success in politics. Political Communication , 33 (2), 188-211. doi:10.1080/10584609.2015.1050565.

Lenz, G.S., \& Lawson, C. (2011). Looking the part: Television leads less informed citizens to vote based on candidates' appearance. American Journal of Political Science, 55, 574-589. doi:10.1111/j.1540-5907.2011.00511.x.

Little, A., Burriss, R., Jones, B., \& Roberts, C. (2007). Facial appearance affects voting decisions. Evolution and Human Behavior, 28, 18-27. doi:10.1016/j.evolhumbehav.2006.09.002.

Little, A.C., Roberts, S.C., Jones, B.C., \& Debruine, L.M. (2012). The perception of attractiveness and trustworthiness in male faces affects hypothetical voting decisions differently in wartime and peacetime scenarios. Quarterly Journal of Experimental Psychology, 65, 20182032. doi:10.1080/17470218.2012.677048.

Livingston, R.W., \& Pearce, N.A. (2009). The teddy-bear effect: Does having a baby face benefit black chief executive officers? Psychological Science, 20, 1229-1236. doi:10.1111/j.14679280.2009.02431.x. 
Mazur, A., \& Booth, A. (1998). Testosterone and dominance in men. The Behavioral and Brain Sciences, 21, 353-363; discussion 363-97.

Nelson, M., \& Shavitt, S. (2002). Horizontal and vertical individualism and achievement values: A multimethod examination of Denmark and the United States. Journal of Cross-Cultural Psychology, 33, 439-458.

Nettle, D., \& Dunbar, R.I.M. (1997). Social markers and the evolution of reciprocal exchange. Current Anthropology, 93-99.

Olivola, C., Eubanks, D., \& Lovelace, J. (2014). The many (distinctive) faces of leadership: Inferring leadership domain from facial appearance. The Leadership Quarterly, 25, 817834.

Olivola, C.Y., \& Todorov, A. (2010a). Elected in 100 milliseconds: Appearance-based trait inferences and voting. Journal of Nonverbal Behavior, 34, 83-110. doi:10.1007/s10919009-0082-1.

Olivola, C.Y., \& Todorov, A. (2010b). Fooled by first impressions? Reexamining the diagnostic value of appearance-based inferences. Journal of Experimental Social Psychology, 46, 315324. doi:10.1016/j.jesp.2009.12.002.

Oosterhof, N.N., \& Todorov, A. (2008). The functional basis of face evaluation. Proceedings of the National Academy of Sciences, 105, 11087-11092. doi:10.1073/pnas.0805664105.

Penton-Voak, I.S, \& Chen, J.Y. (2004). High salivary testosterone is linked to masculine male facial appearance in humans. Evolution and Human Behavior, 25, 229-241. doi:10.1016/j.evolhumbehav.2004.04.003.

Pettigrew, T.F., \& Tropp, L.R. (2006). A meta-analytic test of intergroup contact theory. Journal of Personality and Social Psychology, 90, 751-783. doi:10.1037/0022-3514.90.5.751. 
Pietraszewski, D., Cosmides, L., \& Tooby, J. (2014). The content of our cooperation, not the color of our skin: An alliance detection system regulates categorization by coalition and race, but not sex. PloS One, 9, e88534. doi:10.1371/journal.pone.0088534.

Popkin, S.L. (1994). The reasoning voter: Communication and persuasion in presidential campaigns. University of Chicago Press.

Poutvaara, P. (2014). Facial appearance and leadership: An overview and challenges for new research. The Leadership Quarterly, 25, 801-804. doi:10.1016/j.leaqua.2014.08.003.

Schyns, B., \& Meindl, J. (2005). An overview of implicit leadership theories and their application in organization practice. In B. Schyns \& J. Meindl (Eds), Implicit leadership theories: Essays and explorations (pp. 15-36). Greenwich: Information Age Publishing.

Sell, A., Cosmides, L., Tooby, J., Sznycer, D., von Rueden, C., \& Gurven, M. (2009). Human adaptations for the visual assessment of strength and fighting ability from the body and face. Proceedings of the Royal Society of London B: Biological Sciences, 276, 575-584.

Sell, A., Tooby, J., \& Cosmides, L. (2009). Formidability and the logic of human anger. Proceedings of the National Academy of Sciences, 106, 15073-15078. doi:10.1073/pnas.0904312106.

Sherif, M., Harvey, O.J., Hood, W.R., Sherif, C.W., \& White, J. (1988). The robbers cave experiment: Intergroup conflict and cooperation. 1st Wesleyan Ed edition. Middletown: Wesleyan.

Spisak, B.R., Dekker, P.H., Krüger, M., \& van Vugt, M. (2012a). Warriors and peacekeepers: Testing a biosocial implicit leadership hypothesis of intergroup relations using masculine and feminine faces. PLoS ONE, 7, e30399. doi:10.1371/journal.pone.0030399. 
Spisak, B.R., Homan, A.C., Grabo, A., \& Van Vugt, M. (2012b). Facing the situation: Testing a biosocial contingency model of leadership in intergroup relations using masculine and feminine faces. The Leadership Quarterly, 23, 273-280. doi:10.1016/j.leaqua.2011.08.006.

Stirrat, M., \& Perrett, D.I. (2010). Valid facial cues to cooperation and trust male facial width and trustworthiness. Psychological Science, 21, 349-354. doi:10.1177/0956797610362647.

Sugiyama, L.S. (2004). Illness, injury, and disability among Shiwiar forager-horticulturalists: Implications of health-risk buffering for the evolution of human life history. American Journal of Physical Anthropology, 123, 371-389. doi:10.1002/ajpa.10325.

Thompson, L., \& R. Vecchio (2009). Situational leadership theory: A test of three versions. The Leadership Quarterly, 20, 837-848.

Tiddeman, B.P., Stirrat, M.R., \& Perrett, D.I. (2005). Towards realism in facial image transformation: Results of a Wavelet MRF Method. Computer Graphics Forum, 24, 449456. doi:10.1111/j.1467-8659.2005.00870.x.

Todorov, A., Mandisodza, A.N., Goren, A., \& Hall, C.C. (2005). Inferences of competence from faces predict election outcomes. Science, 308, 1623-1626. doi:10.1126/science.1110589.

Tooby, J., \& Cosmides, L. (1992). The psychological foundations of culture. In J.L. Barkow, L. Cosmides, \& J. Tooby (Eds), The adapted mind: evolutionary psychology and the generation of culture (pp. 19-136). New York: Oxford University Press.

Třebický, V., Havlíček, J., Roberts, S.C., Little, A.C., \& Kleisner, K. (2013). Perceived aggressiveness predicts fighting performance in mixed-martial-arts fighters. Psychological Science, July, 0956797613477117. doi:10.1177/0956797613477117.

van Vugt, M., \& Ahuja, A. (2011). Naturally selected: The evolutionary science of leadership. New York: HarperBusiness. 
van Vugt, M., \& De Cremer, D. (1999). Leadership in social dilemmas: The effects of group identification on collective actions to provide public goods. Journal of Personality and Social Psychology, 76, 587-599. doi:10.1037/0022-3514.76.4.587.

van Vugt, M., \& Grabo, A.E. (2015). The many faces of leadership an evolutionary-psychology approach. Current Directions in Psychological Science, 24, 484-489. doi:10.1177/0963721415601971.

van Vugt, M., Hogan, R., \& Kaiser, R.B. (2008). Leadership, followership, and evolution: Some lessons from the past. The American Psychologist, 63, 182-196. doi:10.1037/0003066X.63.3.182.

von Rohr, C.R., Koski, S.E., Burkart, J.M., Caws, C., Fraser, O.N., Ziltener, A., \& van Schaik, C.P. (2012). Impartial third-party interventions in captive chimpanzees: A reflection of community concern. PLoS ONE, 7, doi:10.1371/journal.pone.0032494.

von Rueden, C, \& van Vugt, M. (2015). Leadership in small-scale societies: Some implications for theory, research, and practice. The Leadership Quarterly, 26, 978-990.

von Rueden, C., Gurven, M., Kaplan, H., \& Stieglitz, J. (2014). Leadership in an egalitarian society. Human Nature, 25, 538-566. doi:10.1007/s12110-014-9213-4.

Zilioli, S., Sell, A.N., Stirrat, M., Jagore, J., Vickerman, W., \& Watson, N.V. (2014). Face of a fighter: Bizygomatic width as a cue of formidability. Aggressive Behavior, 41 (4) doi:10.1002/ab.21544. 


\section{Figures}

a) Average non-dominant and dominant faces
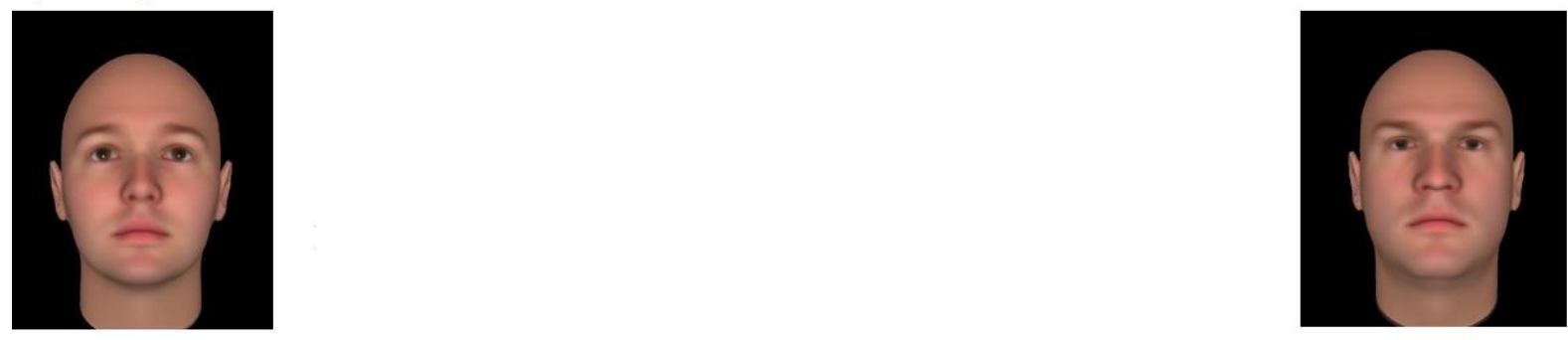

b) Ethnically similar candidate

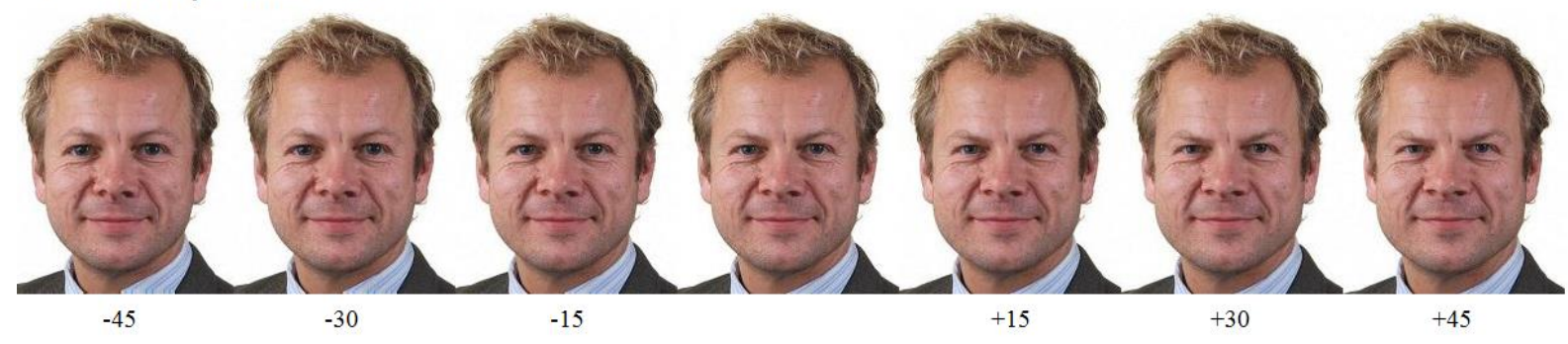

c) Ethnically different candidate

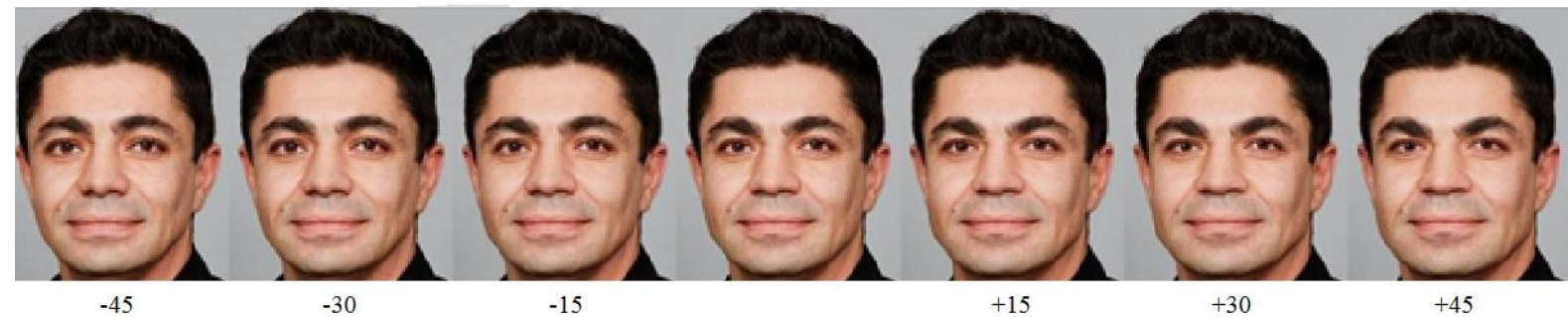

Figure 1. Anchors used for morphing procedure (panel a) and examples of morphed candidate faces for one ethnically similar candidate (panel b) and one ethnically different candidate (panel c). 
a) Horizontal and vertical exploitation scenarios

\begin{tabular}{|c|c|}
\hline Horizontal exploitation & Vertical exploitation \\
\hline \multicolumn{2}{|c|}{ Imagine that you are going to elect a new governor in your state. } \\
\hline $\begin{array}{l}\text { Over the past years the state has been facing } \\
\text { serious problems with gang members who harass } \\
\text { and exploit ordinary citizens and collect welfare } \\
\text { benefits without contributing to society. }\end{array}$ & $\begin{array}{l}\text { Over the past years the state has been facing } \\
\text { serious problems with corrupt governors who are } \\
\text { unresponsive to the needs of ordinate citizens and } \\
\text { exploit their power for personal gain. }\end{array}$ \\
\hline \multicolumn{2}{|c|}{$\begin{array}{l}\text { It is therefore important that the new governor has the right qualities to stop this unfortunate } \\
\text { development. Below you see pictures of two different individuals. Please indicate which individual you } \\
\text { would elect for the job as governor. }\end{array}$} \\
\hline
\end{tabular}

b) Average non-dominant and dominant faces
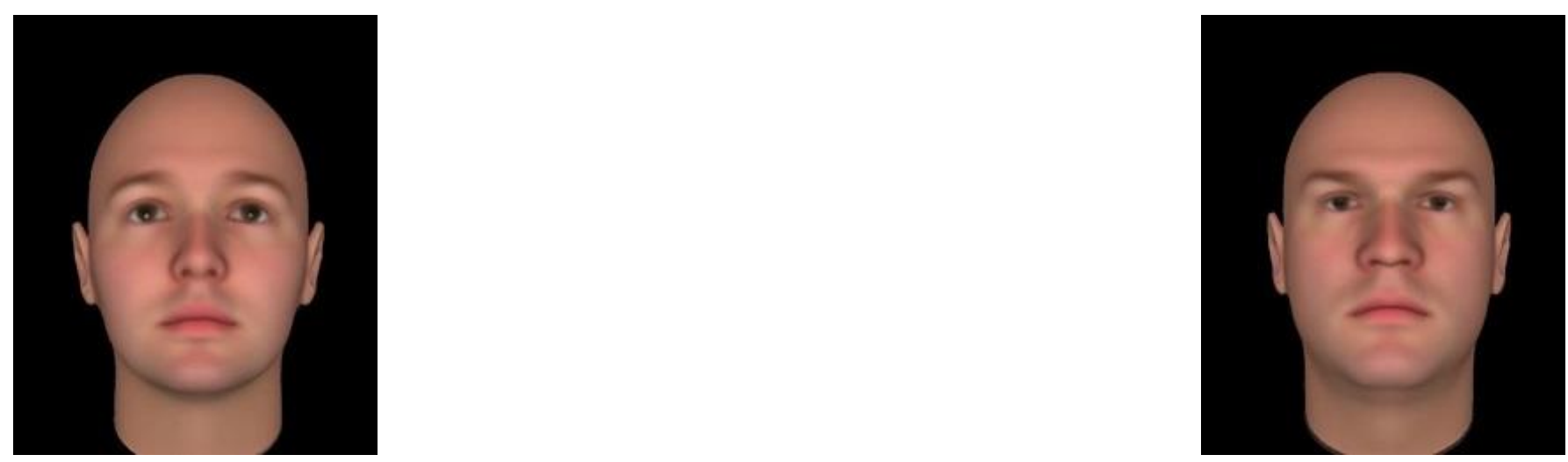

Figure 2: Horizontal and vertical exploitation scenarios (panel a) and dominant (to the right) and non-dominant (to the left) faces (panel b) (used in Study 1). 


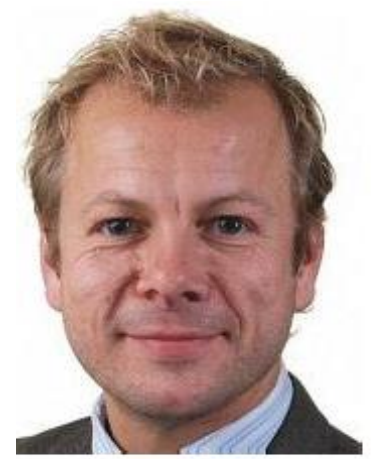

$-45$

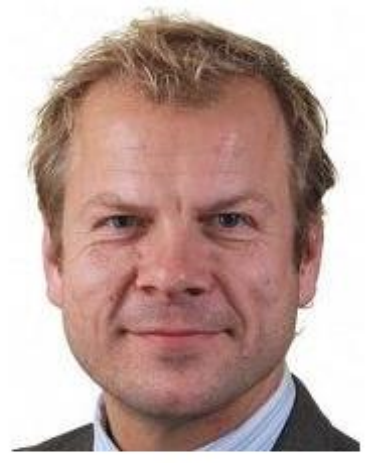

$+45$

Figure 3: Non-dominant (to the left) and Dominant (to the right) faces of candidate Heikki Holmås (used in Study 2). 


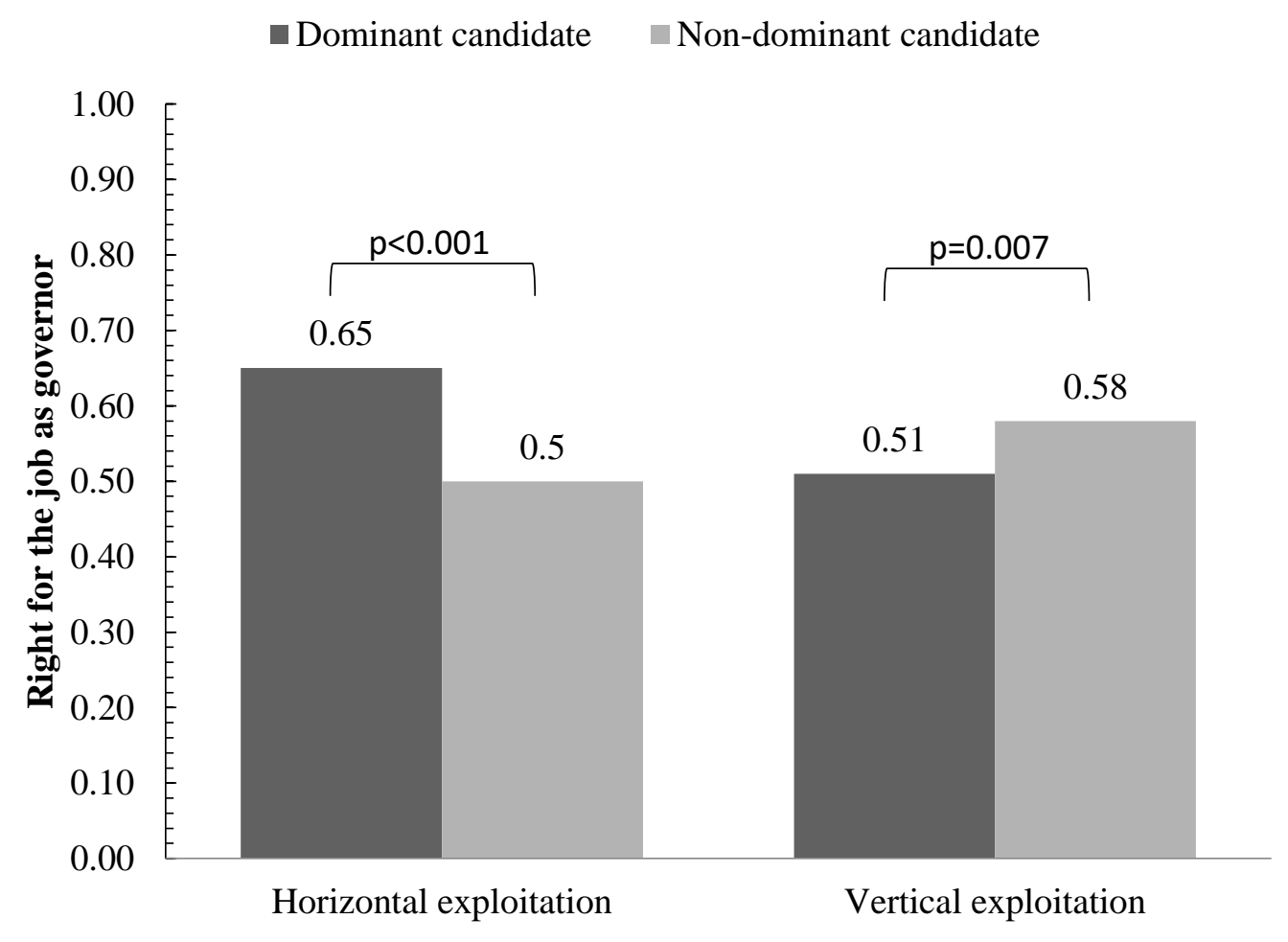

Note: T-tests are two-sided. N=391.

Figure 4. Differences in preferences for dominant and non-dominant candidate across the horizontal and vertical exploitation scenario (Study 2). 
Candidate 1: Heikki Holmås

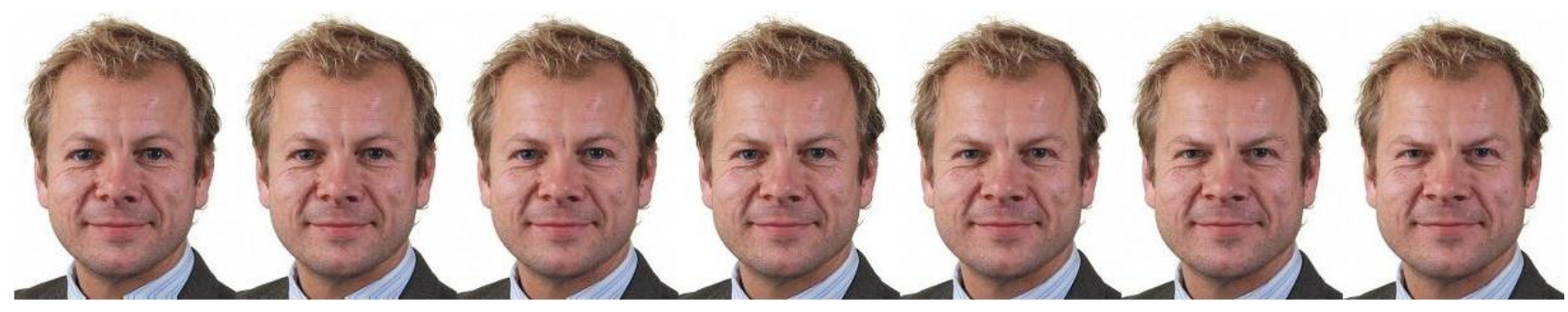

Candidate 2: Kårstein Løvaas

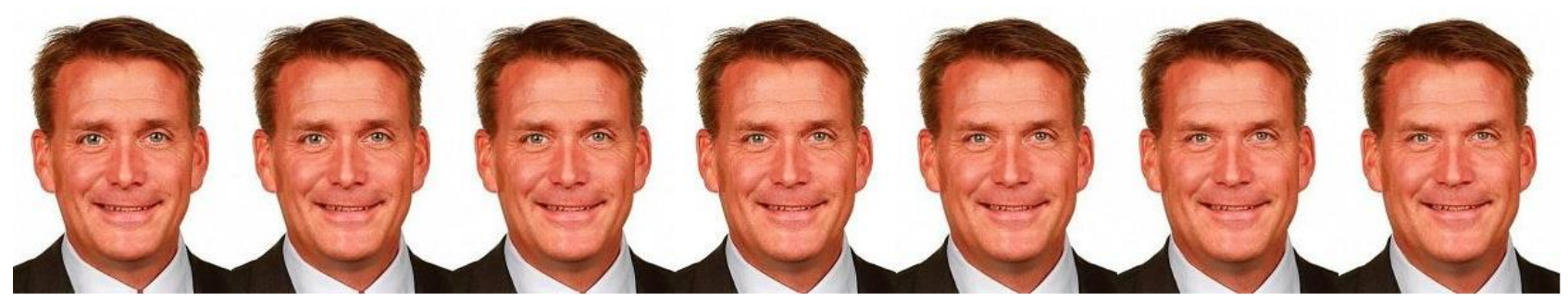

Candidate 3: Helge Orten

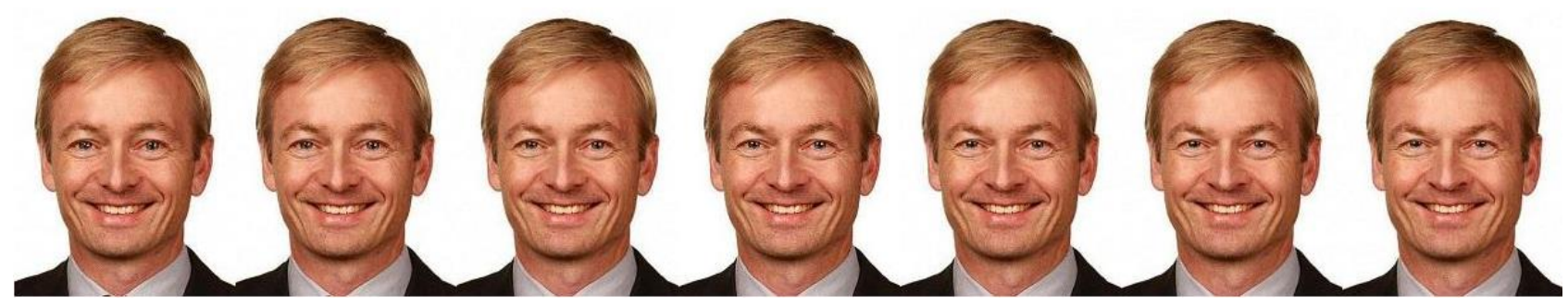

$\underline{\text { Candidate 4: Jan Sanner }}$

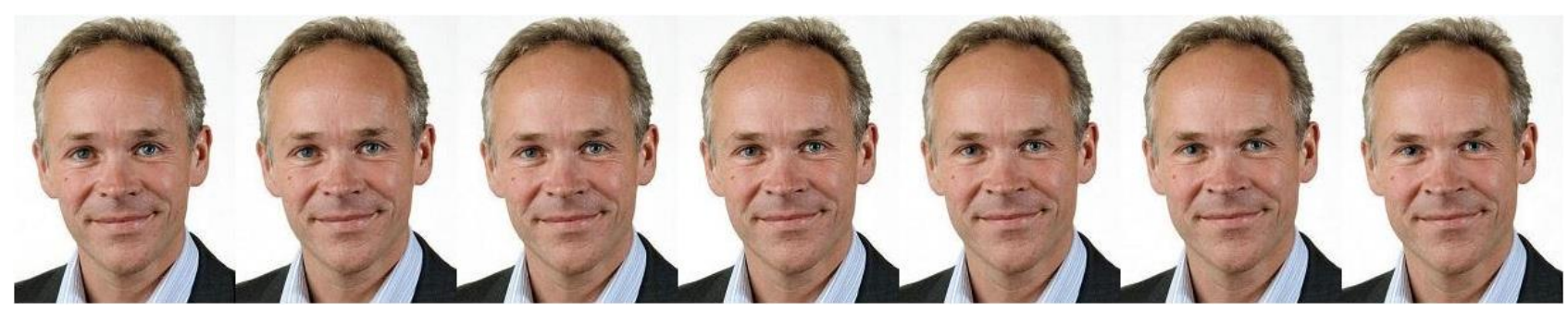

Figure 5: Facial dominance scales of ethnically similar candidates (Study 3 and 4) 
Candidate 5: Abbas Razvi

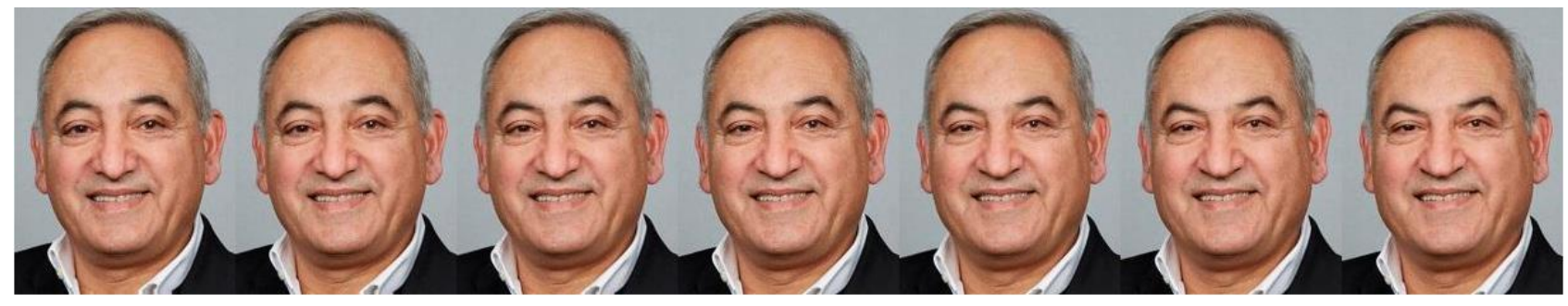

Candidate 6: Hanif Bali

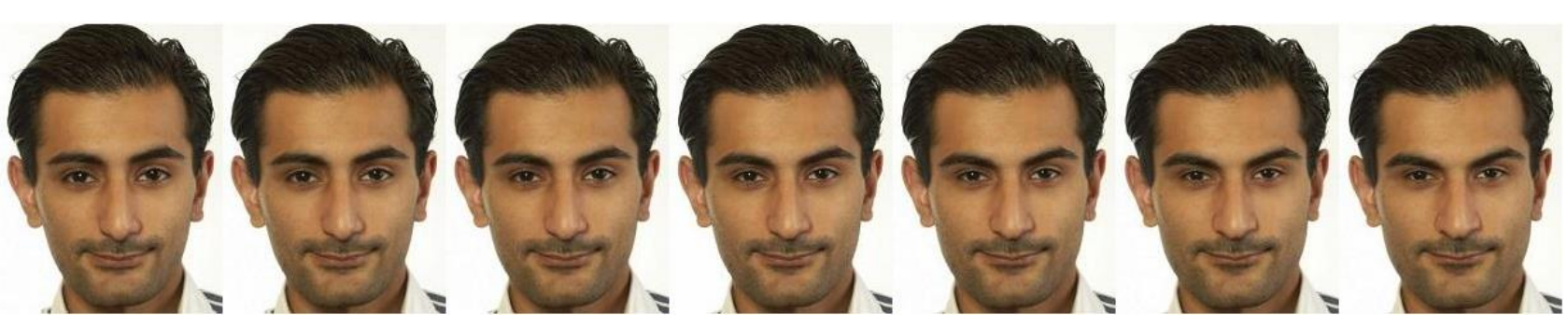

Candidate 7: Naser Khader
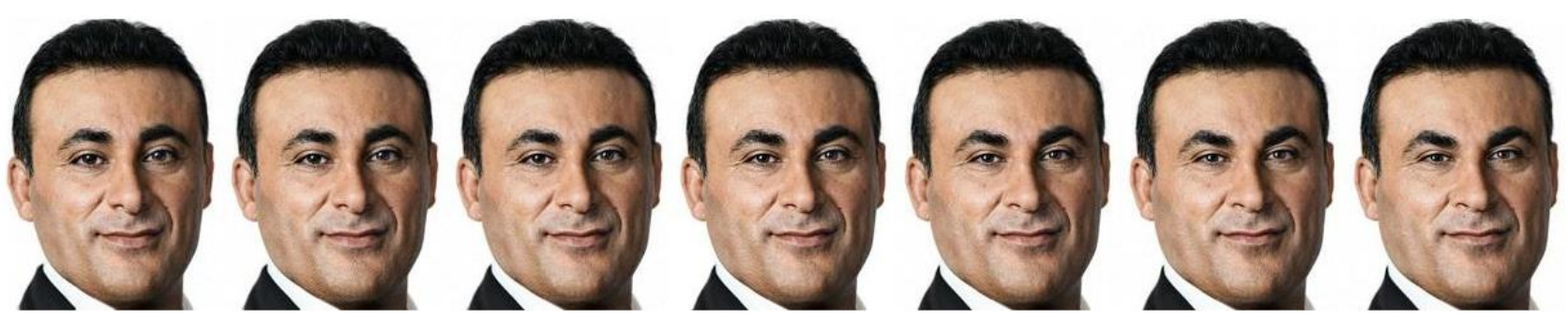

Candidate 8: Özkan Kocak

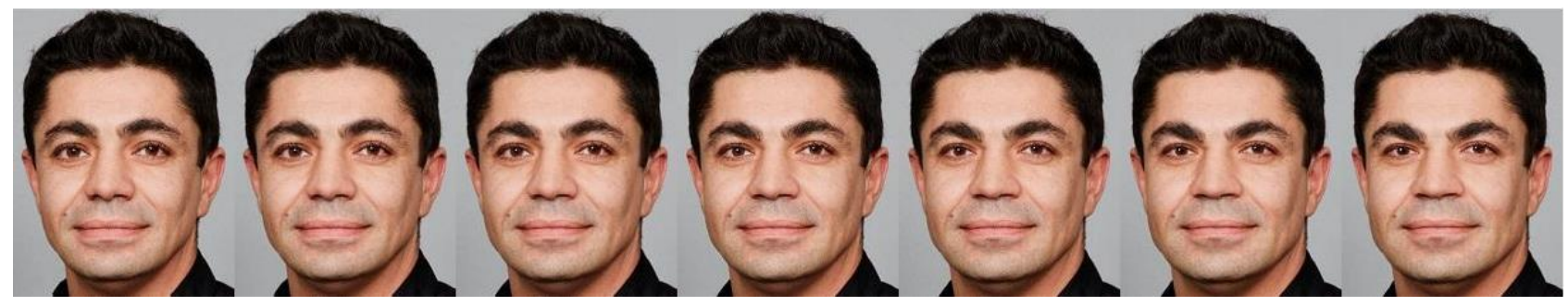

Figure 6: Facial dominance scales of ethnically different candidates (Study 4) 
a)

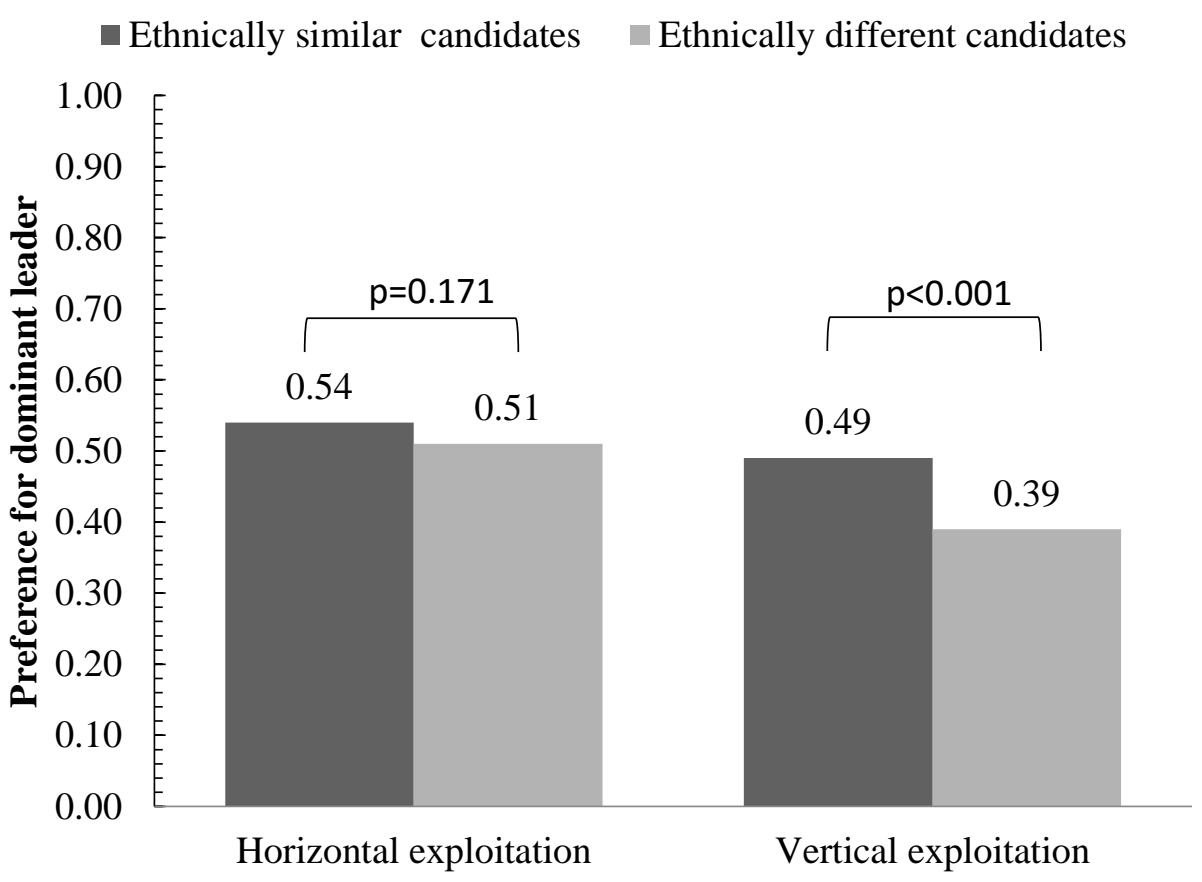

b)

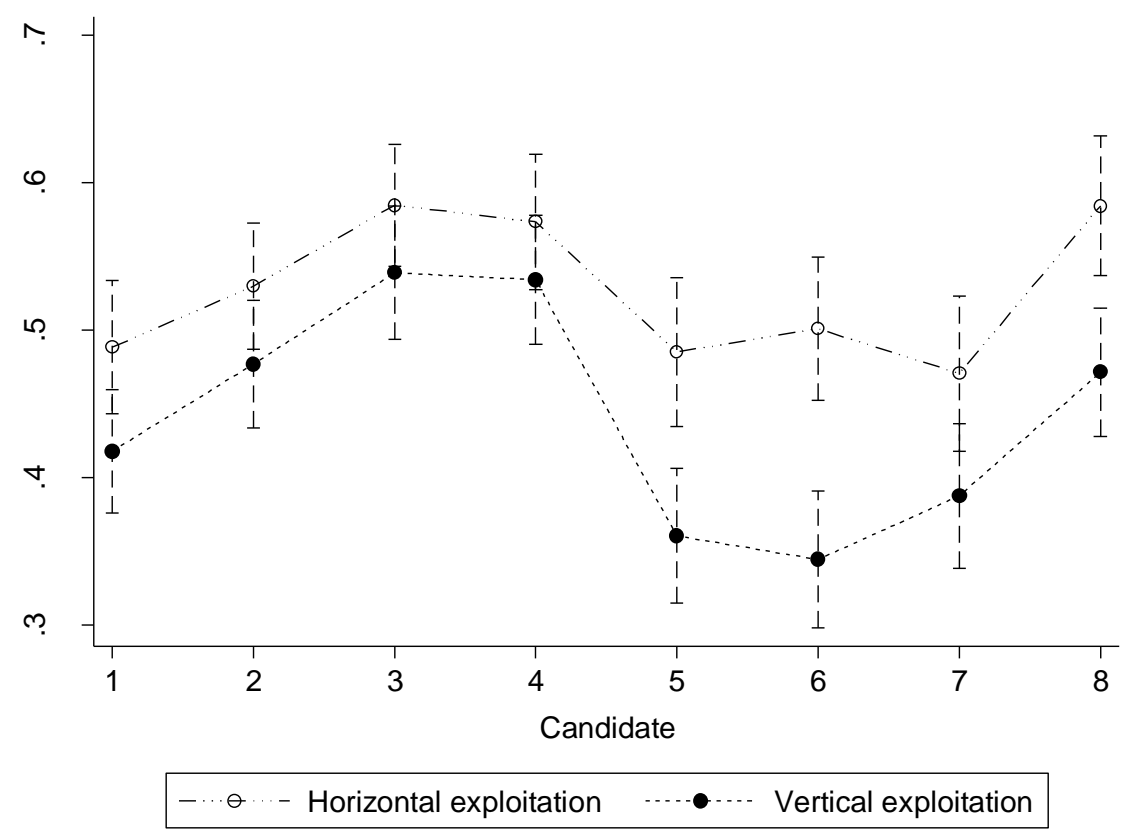

Figure 7. Panel a shows differences in preference for facial dominance in candidates across context and candidate ethnicity ( $\mathrm{p}$-values are from two-sided tests of significance). Panel $\mathrm{b}$ presents average preferences for facial dominance within each candidate depending on contextual condition. Candidate 1-4 are ethnically similar candidates, and Candidate 5-8 are ethnically different candidates (dashed lines are 95 percent confidence intervals) (Study 4). 


\section{Tables}

Table 1. Effects of Candidate dominance, Horizontal-Vertical exploitation and interaction between these variables on Evaluation of Politician (Study 2).

\section{Evaluation of Politician}

\begin{tabular}{lc}
\hline Constant & $.497 * * *$ \\
& $(.017)$ \\
Dominant candidate & $0.156 * * *$ \\
& $(.026)$ \\
Vertical exploitation & $.086 * *$ \\
& $(.028)$ \\
Dominant*Vertical & $-.233 * * *$ \\
& $(.040)$ \\
\hline $\mathbf{N}$ & 391 \\
Adj. $\mathbf{R}^{\mathbf{2}}$ & 0.098
\end{tabular}

Note: ${ }^{*}{ }^{* *},{ }^{* * *}$ : Significant at $\mathrm{p} \leq 0.05, \mathrm{p} \leq 0.01, \mathrm{p} \leq 0.001$. Entries are unstandardized coefficients from an OLS regression model with standard errors in parentheses. All variables are recoded $0-1$. All tests are two-sided. N=391 
Table 2. Effect of Horizontal-Vertical condition on preference for facial dominance in candidates (Model 2.1). Models 2.2. and 2.3 further include candidate dummies (Model 2.2.) and interactions between Horizontal-Vertical condition and cand. dummies (Model 2.3) (Study 3).

\begin{tabular}{|c|c|c|c|}
\hline & $\begin{array}{l}\text { Model 2.1: } \\
\text { Context Effect }\end{array}$ & $\begin{array}{l}\text { Model 2.2: } \\
\text { Context Effect w. } \\
\text { Cand. Dummies }\end{array}$ & $\begin{array}{l}\text { Model 2.3: } \\
\text { Context Effect w. } \\
\text { Cand. Dummy } \\
\text { Interactions }\end{array}$ \\
\hline Constant & $0.530 * * *(0.020)$ & $0.504 * * *(0.023)$ & $0.507 * * *(0.026)$ \\
\hline Vertical Exploitation & $-0.121 * * *(0.027)$ & $-0.121 * * *(0.027)$ & $-0.125 * * *(0.035)$ \\
\hline \multicolumn{4}{|l|}{ Candidate } \\
\hline - $\quad$ Candidate 2 & - & $0.006(0.018)$ & $-0.007(0.026)$ \\
\hline - Candidate 3 & - & $0.043 *(0.019)$ & $0.033(0.026)$ \\
\hline - $\quad$ Candidate 4 & - & $0.052 * *(0.019)$ & $0.066^{*}(0.029)$ \\
\hline \multicolumn{4}{|l|}{ Vertical*Candidate } \\
\hline - $\quad$ Vert.*Cand. 2 & - & - & $0.024(0.036)$ \\
\hline - $\quad$ Vert.*Cand. 3 & - & - & $0.020(0.038)$ \\
\hline - $\quad$ Vert.*Cand. 4 & - & - & $-0.028(0.038)$ \\
\hline Nobservations & 1,248 & 1,248 & 1,248 \\
\hline $\mathbf{R}^{2}$ & 0.038 & 0.043 & 0.045 \\
\hline
\end{tabular}

Note: $* * *, * * *$ : Significant at $\mathrm{p} \leq 0.05, \mathrm{p} \leq 0.01, \mathrm{p} \leq 0.001$. Entries are unstandardized coefficients from an OLS regression with standard errors clustered at the subject level in parentheses. Reference categories are: Horizontal exploitation (for context); Candidate 1 (for Candidate). All variables are recoded 0-1. All tests are two-sided. $\mathrm{N}_{\text {subjects }}=312$ 
Table 3. Effects of Ethnically similar-different manipulation, Horizontal-Vertical exploitation manipulation (Model I) and interaction between these variables (Model II) on preference for dominant leader (Study 4).

\begin{tabular}{|c|c|c|c|c|}
\hline & $\begin{array}{l}\text { Model 3.1: } \\
\text { Context \& } \\
\text { Ethnicity }\end{array}$ & $\begin{array}{c}\text { Model 3.2: } \\
\text { Context \& Cand. } \\
\text { Dummies }\end{array}$ & $\begin{array}{c}\text { Model 3.3: } \\
\text { Context w. Cand. } \\
\text { Dummy Interactions }\end{array}$ & $\begin{array}{c}\text { Model 3.4: } \\
\text { Context \& } \\
\text { Ethnicity } \\
\text { interaction }\end{array}$ \\
\hline Constant & $0.561 * * *(0.014)$ & $0.495^{* * *}(0018)$ & $0.489 * * *(0.023)$ & $0.544 * * *(0.016)$ \\
\hline Vertical Exploitation & $-0.084 * * *(0.017)$ & $-0.084 * * *(0.017)$ & $-0.071 *(0.031)$ & $-0.052 *(0.022)$ \\
\hline Ethnically different & $-0.068 * * *(0.017)$ & - & - & $-0.034(0.025)$ \\
\hline Vertical*Ethnically diff. & - & - & - & $-0.067 *(0.034)$ \\
\hline \multicolumn{5}{|l|}{ Candidate } \\
\hline - Candidate 2 & - & $0.051 * *(0.018)$ & $0.041(0.027)$ & - \\
\hline - $\quad$ Candidate 3 & - & $0.109^{* * *}(0.018)$ & $0.096^{* * * *}(0.024)$ & - \\
\hline - $\quad$ Candidate 4 & - & $0.101 * * *(0.018)$ & $0.085 * *(0.026)$ & - \\
\hline - Candidate 5 & - & $-0.031(0.023)$ & $-0.003(0.034)$ & - \\
\hline - $\quad$ Candidate 6 & - & $-0.031(0.023)$ & $0.013(0.034)$ & - \\
\hline - $\quad$ Candidate 7 & - & $-0.024(0.024)$ & $-0.018(0.035)$ & - \\
\hline - $\quad$ Candidate 8 & - & $0.074 * * *(0.023)$ & $0.095 * *(0.033)$ & - \\
\hline \multicolumn{5}{|l|}{ Vertical*Candidate } \\
\hline - $\quad$ Vert.*Candidate 2 & - & - & $0.018(0.037)$ & - \\
\hline - $\quad$ Vert. $*$ Candidate 3 & - & - & $0.025(0.036)$ & - \\
\hline - $\quad$ Vert. $*$ Candidate 4 & - & - & $0.031(0.036)$ & - \\
\hline - Vert. *Candidate 5 & - & - & $-0.054(0.047)$ & - \\
\hline - $\quad$ Vert.*Candidate 6 & - & - & $-0.086(0.046)$ & - \\
\hline - $\quad$ Vert.*Candidate 7 & - & - & $-0.012(0.048)$ & - \\
\hline - $\quad$ Vert.*Candidate 8 & - & - & $-0.042(0.045)$ & - \\
\hline Nobservations & 2,524 & 2,524 & 2,524 & 2,524 \\
\hline $\mathbf{R}^{2}$ & 0.032 & 0.053 & 0.057 & 0.035 \\
\hline
\end{tabular}

Note: ${ }^{* * *},{ }^{* * *}$ : Significant at $\mathrm{p} \leq 0.05, \mathrm{p} \leq 0.01, \mathrm{p} \leq 0.001$. Entries are unstandardized coefficients from an OLS regression with standard errors clustered at the subject level in parentheses. Reference categories are: Horizontal exploitation (for context); Ethnically similar (for Ethnicity); Candidate 1 (for Candidate). All variables are recoded $0-1$. All tests are two-sided. $\mathrm{N}_{\text {subjects }}=631$ 
Appendix A. Horizontal and vertical exploitation scenarios (Study 3 and 4).

\begin{tabular}{|c|c|}
\hline Horizontal exploitation & Vertical exploitation \\
\hline \multicolumn{2}{|c|}{$\begin{array}{l}\text { Imagine that you are going to elect a new mayor (governor) in your municipality. The mayor (governor) } \\
\text { has some particularly important tasks. }\end{array}$} \\
\hline $\begin{array}{l}\text { He must exhibit strong leadership to coordinate } \\
\text { government work in the municipality and make } \\
\text { sure that all citizens behave in accordance with the } \\
\text { laws and norms of society. }\end{array}$ & $\begin{array}{l}\text { He must be responsive to the needs and wishes of } \\
\text { regular citizens in the municipality and make sure } \\
\text { that all stakeholders are heard before important } \\
\text { decisions are made. }\end{array}$ \\
\hline $\begin{array}{l}\text { In his daily work, it is therefore important that the } \\
\text { mayor (governor) takes a tough line with citizens } \\
\text { who disrupt social order and actively seek to } \\
\text { obstruct the development and prosperity of the } \\
\text { municipality. }\end{array}$ & $\begin{array}{l}\text { In his daily work, it is therefore important that the } \\
\text { mayor (governor) focuses on the interests of } \\
\text { citizens rather than bending the rules and } \\
\text { exploiting his powerful position to advance his } \\
\text { own personal career. }\end{array}$ \\
\hline ou see the same politician in 7 different $\mathrm{V}$ & s. Pleas \\
\hline
\end{tabular}

Figure 5: Horizontal and vertical exploitation scenarios (Study 3 and 4). 